\title{
Article \\ The Effect of Specimen Size and Test Procedure on the Creep Behavior of ME21 Magnesium Alloy
}

\author{
Bettina Camin *(D) and Maximilian Gille
}

Faculty III-Process Sciences, Institute of Materials Sciences and Technology, Technische Universität Berlin, Sekr. BH18, Ernst-Reuter-Platz 1, 10587 Berlin, Germany; gille@tu-berlin.de

* Correspondence: camin@physik.tu-berlin.de; Tel.: +49-30-314-22096

Citation: Camin, B.; Gille, M. The Effect of Specimen Size and Test Procedure on the Creep Behavior of ME21 Magnesium Alloy. Crystals 2021, 11, 918. https://doi.org/ $10.3390 /$ cryst11080918

Academic Editors: Umberto Prisco and Bolv Xiao

Received: 3 July 2021

Accepted: 5 August 2021

Published: 7 August 2021

Publisher's Note: MDPI stays neutral with regard to jurisdictional claims in published maps and institutional affiliations.

Copyright: (c) 2021 by the authors. Licensee MDPI, Basel, Switzerland. This article is an open access article distributed under the terms and conditions of the Creative Commons Attribution (CC BY) license (https:// creativecommons.org/licenses/by/ $4.0 /)$.

\begin{abstract}
Lightweight constructions and materials offer the opportunity to reduce $\mathrm{CO}_{2}$ emissions in the transport sector. As components in vehicles are often exposed to higher temperatures above $40 \%$ of the melting temperature, there is a risk of creep. The creep behavior usually is investigated based on standard procedures. However, lightweight constructions frequently have dimensions not adequately represented by standardized specimen geometries. Therefore, comparative creep experiments on non-standardized miniature and standardized specimens are performed. Due to a modified test procedure specified by a miniature creep device, only the very first primary creep stage shows a minor influence, but subsequently, no effect on the creep process is detected. The creep behavior of hot extruded and heat treated ME21 magnesium alloy is investigated. It is observed that the creep parameters determined by the miniature and standard creep tests are different. As the deviations are systematic, qualitatively, evidence of the creep behavior is achieved. The creep parameters obtained, and particularly the creep strain and the strain rate, show a higher creep resistance of the miniature specimen. An initial higher number of twinned grains and possible multiaxiality in the gauge volume of the miniature specimen can be responsible.
\end{abstract}

Keywords: creep testing; ME21; magnesium alloy; size effects; miniature specimen

\section{Introduction}

Since the signing of the Kyoto Protocol and a steadily increasing understanding of the effects of $\mathrm{CO}_{2}$ emissions on the earth's climate, industry is interested in optimizing its processes and designs regarding $\mathrm{CO}_{2}$ reduction. In the transport sector, in particular, the goal is to lower the overall weight of vehicles, aircraft, and rail vehicles to decrease fuel consumption and thus environmental pollution. In this context, the terms green technology and life cycle costs focus on product development. Connecting factors are lightweight constructions and materials as well as energy-saving manufacturing processes.

In the latter, characterizing the mechanical and thermo-mechanical properties of alloys is critical in developing novel non- or low-contaminant construction and production technologies as well as during operation. Hence, the investigation of titanium [1,2], aluminum [3], and magnesium alloys [4] as lightweight materials under extreme conditions is of particular interest. Mainly, it is essential to depict the responses of structural components to external mechanical loadings [5,6]. Although the mechanical loads investigated in this work are relatively moderate nevertheless, small dimensions additionally exposed to high temperature can already be rated as highly loaded during service.

In lightweight constructions, modifications of the design by wall thickness reduction are further solutions in this context. As these components are subjected to mechanical loads at room temperature and higher temperatures, their creep resistance is of great importance. Typically, creep experiments are performed on standardized samples according to, e.g., DIN EN ISO 204 (European Standard) [7] or ASTM E139 (American Standard) [8]. However, complex or thin-walled lightweight component geometries partially do not 
allow standardized specimens to be taken. Consequently, there has been a high interest in carrying out investigations on miniaturized specimen geometries. Furthermore, the smaller dimensions of the specimens enable detailed investigations of representative material states from components, whereby the miniature specimens can be taken in different orientations from a small material volume [9-12]. The influence of the creep parameters by the specimen sizes is provided, and the test method is known. However, the confidence of these results compared to standard sample sizes is of great importance. Miniature specimens, or creep specimens with non-standard geometry, have been used for some time to investigate steel's creep behavior in power plant construction, e.g., [13-18]. Pipelines and connectors are components subjected to creep stresses, which cannot be investigated reproducibly with the geometry of standard creep specimens.

However, especially in the transport sector, replacing construction materials such as steel with lightweight materials effectively reduces weight $[19,20]$. In addition to aluminum and titanium lightweight materials, the magnesium alloys show a high application potential for the mentioned requirements as they have the lowest density $\left(1.74 \mathrm{~g} / \mathrm{cm}^{-3}\right)$ and high specific strength and stiffness compared to all other metallic construction materials. However, most magnesium alloy's poor forming properties and creep resistance due to their hexagonal closed packed (hcp) structure currently severely limit their industrial application [19,21,22]. The magnesium wrought alloy ME21 containing rare earth (RE) element cerium and the element manganese is characterized by good formability at higher temperatures, corrosion, and creep resistance compared to other Mg alloys [19,23-31]. Ce is added to increase the high-temperature strength and creep resistance due to its pronounced solid solution hardening and low diffusion tendency [25]. Furthermore, the intermetallic phase $\mathrm{Mg}_{12} \mathrm{Ce}$ formed at grain boundaries prevents grain boundary sliding. Its good formability enables the production of thin sheets with a thickness of $1 \mathrm{~mm}$. However, studies on the creep behavior of the magnesium alloy ME21 are rare. The creep properties of the ME21 alloy are of interest providing a more cost-effective and resource-saving alternative to the WE43 and WE54 alloys containing a higher amount of expensive rare earth elements currently used for components subjected to creep [20,32]. The compositions of the alloys ME21, WE43, and WE54 are given in Table 1 (c.f. Section 2.1).

Additionally, energy-saving manufacturing technologies are selected, enabling the final product to be manufactured with as few manufacturing steps as possible. For this purpose, the manufacturing process by hot extrusion for transport assemblies is established and used for many years, e.g., [33-36]. The production of larger components up to thin sheets of various materials is possible with this process.

As many assemblies in the transportation sector-including lightweight structuresare manufactured nowadays by hot extrusion, in this work, comparative creep experiments of the hot extruded magnesium alloy ME21 are carried out. Miniature and standard specimen geometries are investigated, the creep behavior itself, as well as the influence due to downsizing, are validated.

\section{Materials and Methods}

\subsection{Material}

The aluminum-free magnesium alloy ME21 is alloyed by 2 wt \% Mn and 1 wt \% Ce. The chemical composition is given in Table 1.

Table 1. Chemical composition of ME21 [37], WE43 [38], WE54 [39].

\begin{tabular}{ccccccccccccc}
\hline & Mn & Ce & Al & Nd & Pr & Si & Th & Y & Zn & Mg \\
\hline ME21 & 2.1 & 0.7 & $\leq 0.01$ & $\leq 0.015$ & $\leq 0.01$ & $\leq 0.015$ & 0.14 & 0.04 & $\leq 0.015$ & bal. \\
\hline & Mn & Li & Ni & Nd & $\mathbf{Z r}$ & Si & Cu & Y & Zn & Mg \\
\hline WE43 & $\leq 0.15$ & $\leq 0.2$ & $\leq 0.005$ & $2.4-4.4$ & $0.4-1.0$ & $\leq 0.01$ & $\leq 0.03$ & $3.7-4.3$ & $\leq 0.2$ & bal. \\
WE54 & $\leq 0.15$ & $\leq 0.2$ & $\leq 0.005$ & $2.0-4.0$ & $0.4-1.0$ & $\leq 0.01$ & $\leq 0.03$ & $4.75-5.5$ & $\leq 0.2$ & bal. \\
\hline
\end{tabular}


The hot extruded cylindrical bars made of ME21 manufactured by an $8 \mathrm{MN}$ horizontal extrusion plant (SMS group $\mathrm{GmbH}$, Düsseldorf, Germany) and provided by the Extrusion Research and Development Center of the Technische Universität Berlin (FZS). The detailed function of the plant and the extrusion process are described in $[40,41]$. Parameters of hot extrusion process such as the initial geometry of the billet, the temperatures of the billet $\vartheta_{b}$, container $\boldsymbol{\vartheta}_{\boldsymbol{a}}$ and tool $\boldsymbol{\vartheta}_{\boldsymbol{w}}$, the extrusion ratio $\boldsymbol{V}$, and product speed $\boldsymbol{v}_{\boldsymbol{p}}$ are shown in Table 2 .

Table 2. Parameters of the hot extrusion process.

\begin{tabular}{cccccc}
\hline Technique & $\begin{array}{c}\text { Billet } \\
\text { Geometry }\end{array}$ & $\boldsymbol{\vartheta}_{\boldsymbol{a}}, \boldsymbol{\vartheta}_{\boldsymbol{b}}, \boldsymbol{\vartheta}_{\boldsymbol{w}}$ & $\boldsymbol{V}$ & $\boldsymbol{v}_{\boldsymbol{p}}$ & Cooling \\
\hline \multirow{2}{*}{ indirect } & $\begin{array}{c}\varnothing=123 \mathrm{~mm} \\
\boldsymbol{l}=150 \mathrm{~mm}\end{array}$ & $450{ }^{\circ} \mathrm{C}$ & 71 & $1.7 \mathrm{~m} \mathrm{~min}^{-1}$ & air \\
\hline
\end{tabular}

After the hot extrusion process, the extruded product in the as extruded condition (as ex) shows a fine-grained microstructure inappropriate for creep resistance. According to Brömmelhoff et al. [42], subsequent heat treatment at $\boldsymbol{T}=550{ }^{\circ} \mathrm{C}$ for 24 hours followed by quenching in water leads to fine-dispersed $\mathrm{Mn}$, bigger $\mathrm{Mg}_{12}$ Ce-precipitates, a coarsegrained and homogeneous microstructure. Optical microscopy (OM) analyses illustrate the microstructure (Figure 1). The grain size varies between 10 and $70 \mu \mathrm{m}$ by an average of $38 \mu \mathrm{m}$, and an aspect ratio of 1 is measured. The visible $\mathrm{Mg}_{12} \mathrm{Ce}$-precipitates marked by a white arrow are homogeneously distributed throughout the microstructure (Figure 1a,c) and are mainly found at the grain boundaries (Figure 1b). Small Mn-precipitates are fine-dispersed in the matrix (Figure 1b, light grey arrows).
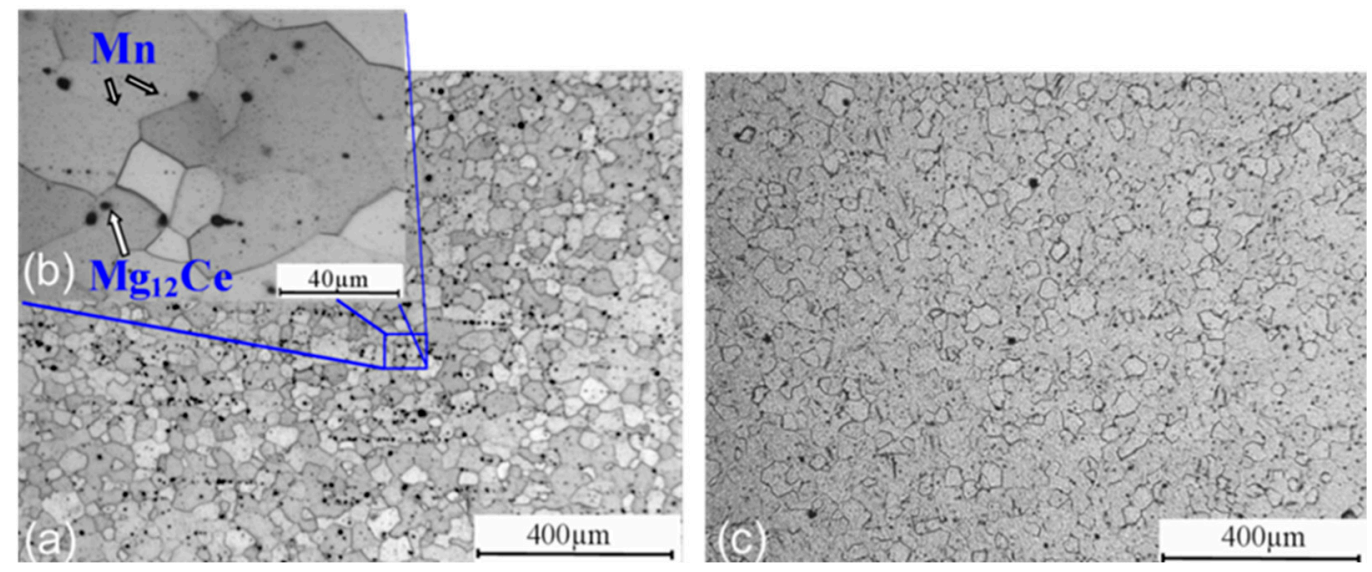

Figure 1. Microstructure of the heat treated ME21 material; (a,b) longitudinal section (=ED), (a) $50 \times$, (b) $500 \times$; (c) cross section, $200 \times$.

\subsection{Microscopy}

The microstructure of the hot extruded and heat-treated initial material and of the miniaturized and standardized samples after the creep experiments is investigated by an optical microscope UnivaR Met (Reichert-Jung Optische Werke AG, Austria) equipped with a digital camera system Leica DFC 295 (Leica Microsystems GmbH, Germany) and by a scanning electron microscope JEOL JSM 640 (JEOL GmbH, Germany) equipped with a Noran detector (Thermo Fisher Scientific Inc., Germany) for EDS measurements. From the initial material sections in the extrusion direction (ED) and perpendicular to ED, the transverse direction (TD), are taken using a cutting-off machine WOCO 50 (Conrad, Germany). The creep-stressed specimens are investigated in ED only.

For metallographic preparation, the specimens are embedded in the two-component epoxy resin Technovit 4071 (Kulzer GmbH, Germany). First, the specimens are manually ground on a polishing and grinding machine, TegraPol-25 (Struers GmbH, Germany), 
followed by manual polishing of the specimens with diamond suspensions (6 to $1 \mu \mathrm{m}$ ). Subsequently, the samples were additionally chemically polished by immersing them in a $\mathrm{CP} 2$ solution for $2 \mathrm{~s}$ to remove near-surface deformation layers resulting from polishing and reopen pores closed by the preparation. The $\mathrm{CP} 2$ solution is made from $100 \mathrm{ml}$ ethanol, $12 \mathrm{ml}$ hydrochloric acid ( 25 percentage), and $8 \mathrm{ml}$ nitric acid. For the OM examination of the microstructure, the sample surfaces are finally etched with a solution of $100 \mathrm{ml}$ ethanol, $20 \mathrm{ml}$ water, $6 \mathrm{ml}$ glacial acetic acid, and $5 \mathrm{~g}$ picric acid for $3 \mathrm{~s}$.

\subsection{Creep Experiments}

This work aims the investigation of the creep behavior of miniature specimens in comparison to specimens with standardized geometries-further referred to as standard specimens-according to DIN EN ISO 204 [7]. The dimensions of both creep specimens are shown in Figure 2.

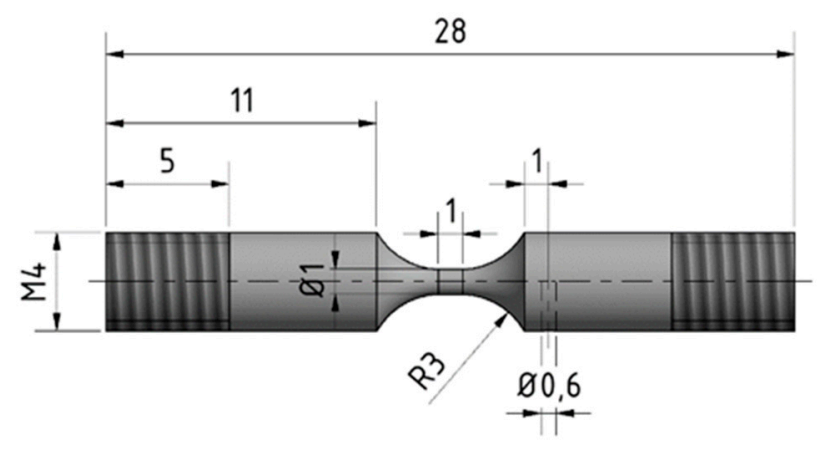

(a)

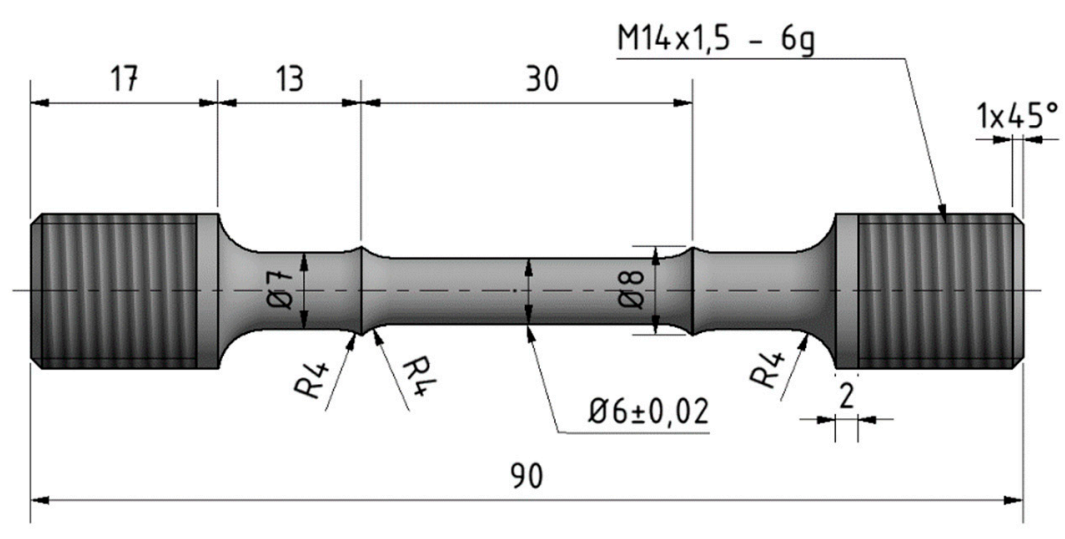

(b)

Figure 2. Geometries of the creep specimens, (a) miniature specimen, (b) standard specimen.

Two different creep devices were used for these studies. The creep tests using standard specimens are performed on a commercial creep testing machine DSM 6102 equipped with a three-stage vertical electric furnace type EO 4090 (Roell Amsler Prüfmaschinen GmbH \& Co. KG, Germany), enabling temperatures up to $1100{ }^{\circ} \mathrm{C}$. The force is applied via an electric motor, whereby the maximum test load of the system is $50 \mathrm{kN}$. The elongation of the sample is determined by an extensometer mechanically adapted directly to the specimen. This ensures only the change in length $\Delta \boldsymbol{l}$ of the specimen's gauge length $l_{g}$ is determined. The creep experiments using miniature specimens are carried out applying a miniature creep device developed by TU Berlin for in situ synchrotron $\mu$-tomography measurements (XCT) at the European Synchrotron Radiation Facility (ESRF) described in detail in [43-46]. In these works and furthermore, in [47-49], the applicability of this miniature creep device 
was shown. It should be mentioned here once again that the experimental procedure of creep experiments conducted by the miniature creep device (cf. [46]) is different from the procedure given by DIN EN ISO 204. Regarding the requirements of in situ XCT investigations at the beamlines of the ESRF, the following aspects are part of the experimental design of the miniature creep device:

- $\quad$ The mechanical load to the sample is applied before heating.

- The ratio of the initial gauge diameter $d_{0}=1 \mathrm{~mm}$ and the initial gauge length $\boldsymbol{l}_{0}=1 \mathrm{~mm}$ of the sample is $\boldsymbol{d}_{0} / \boldsymbol{l}_{0}=1$ (Figure $2 \mathrm{a}$ ).

- The elongation of the whole sample is measured during creep. As shown in [46], compared to the much larger diameter of the clamping, significant strain changes occur only in the small diameter of the gauge volume as soon as the thermal equilibrium is reached.

Comparative preliminary tests on standard samples (Figure 2b) in the DSM 6102 test rig are conducted to investigate the influence of the varied sequence of mechanical and thermal loading on the creep behavior. An uniaxial tensile mechanical load of $\sigma=20 \mathrm{MPa}$ is applied in all preliminary creep tests. The two different test procedures are described as follows:

- In agreement with the standard creep test procedure specified by [7], the mechanical load is applied after the sample is heated up to the test temperature (sequence: heating $\rightarrow$ mechanical loading).

- In agreement with the creep test procedure specified by the miniature creep device, the mechanical load is applied at room temperature, and subsequent, the specimen is heated to the test temperature (sequence: mechanical loading $\rightarrow$ heating).

The analyses of the creep curves measured for both test procedures provide information about the applicability of the different sequences.

Another focus in this work is on comparative investigations of the creep behavior of standard and miniature creep specimens performed according to the test procedure given by the miniature creep device. The miniature specimens are tested in the miniature creep device, and the standard specimens are tested in the DSM 6102 test rig. All creep tests are carried out at a test temperature $T_{c r}=523 \mathrm{~K}$ due to the highest temperature expected in automobiles. Taking the melting temperature of magnesium $T_{m}=923 \mathrm{~K}$ into account, hence, a homologous temperature $T_{\text {homolog }}=T_{c r} / T_{m}=0.58$ results. Mechanical loads $\sigma=10,15,20,25$, and $30 \mathrm{MPa}$ are selected. Due to the work of Stinton et al., phase stability can be expected [50]. For each mechanical load, two experiments are performed with the miniature specimens and one experiment with the standard specimens. Due to measured high strains at fracture $\left(\varepsilon_{f r}>\mathbf{0 . 1}\right)$, the true creep curve $\varepsilon_{\text {true }}=f(t)$ and true strain rate curve $\dot{\varepsilon}_{\text {true }}=f(t)$ are calculated from the elongation of the sample $\Delta \boldsymbol{l}$ measured by extensometer in reference to the initial gauge length $l_{0}$ [51]:

$$
\begin{gathered}
\varepsilon_{\text {true }}=\ln \left(1+\frac{\Delta l}{l_{g}}\right) \\
\dot{\varepsilon}_{\text {true }}=\frac{\varepsilon_{\text {true }}}{\mathrm{d} t}
\end{gathered}
$$

\section{Results}

3.1. Creep Tests

\subsubsection{Preliminary Creep Tests}

The comparison of the creep curves $\varepsilon_{\text {true }}=f(t)$ calculated from Equation (1) and strain rate curves $\dot{\varepsilon}_{\text {true }}=f(t)$ (Equation (2)) obtained in the preliminary creep tests are shown in Figure 3. It should be noted that the true strain is a dimensionless quantity. Overall, both creep curves basically show similar behavior. However, the strain develops differently within approximately first two hours of the creep experiments. While the creep curve of the experiment due to the standard sequence (heating $\rightarrow$ mechanical load) exhibits a typical 
behavior, the behavior of the varied creep test sequence (mechanical load $\rightarrow$ heating) is unusual in the early primary creep stage. After a minor positive initial strain, a negative strain seems to occur here, subsequently increasing again. During heating from room to test temperature under mechanical load competitive processes, time-independent and time-dependent plastic deformation occurs. The mechanisms behind, are not investigated in this work. Afterward, at the latest in the transition from the primary to the secondary stage, the creep curves of both test procedures more or less run parallel to each other. Finally, the creep time until fracture $t_{f r}$ and the creep strain at fracture $\varepsilon_{f r}$ are different (Figure 3a). The strain rate curves illustrate the different behavior in the early primary creep stage (Figure 3b). Apparently, even negative strain rates occur right at the beginning for the miniature specimen. After approximately 4 hours, the curves of both test procedures fit together, while the minimum creep rates $\dot{\varepsilon}_{\min }$ are quite similar. The difference of the two measured values for the minimum creep rate is less than $4 \%$, which is within typical experimental error limits. The changed sequence of the test procedure has no significant influence on the minimum creep rate determined for the given test parameters.

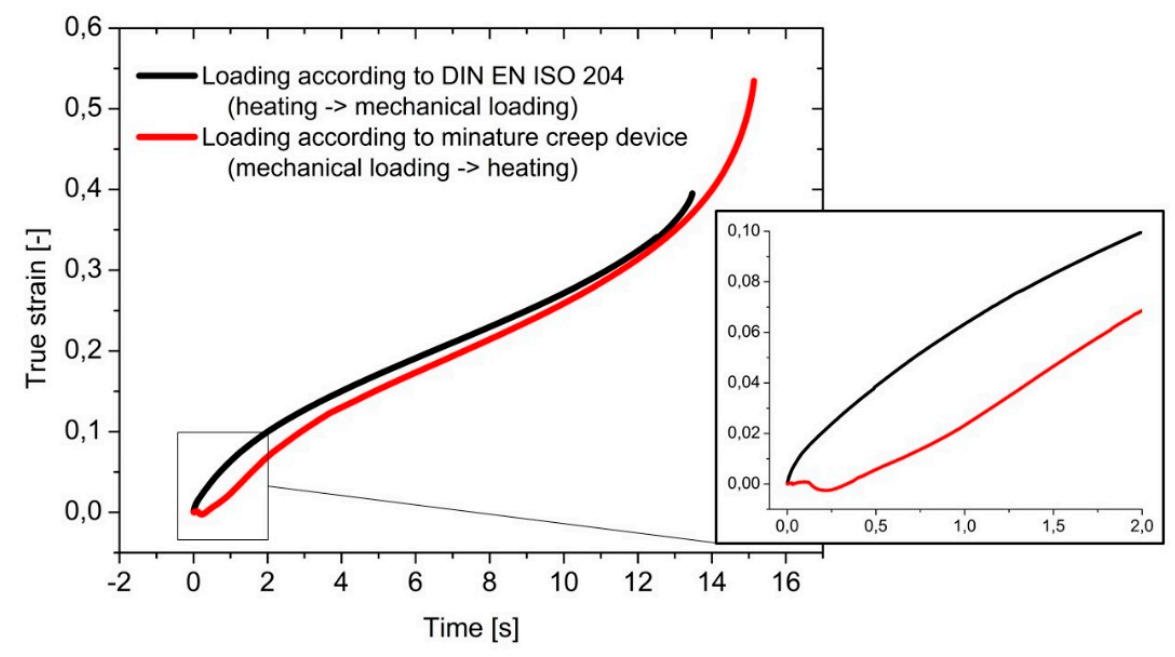

(a)

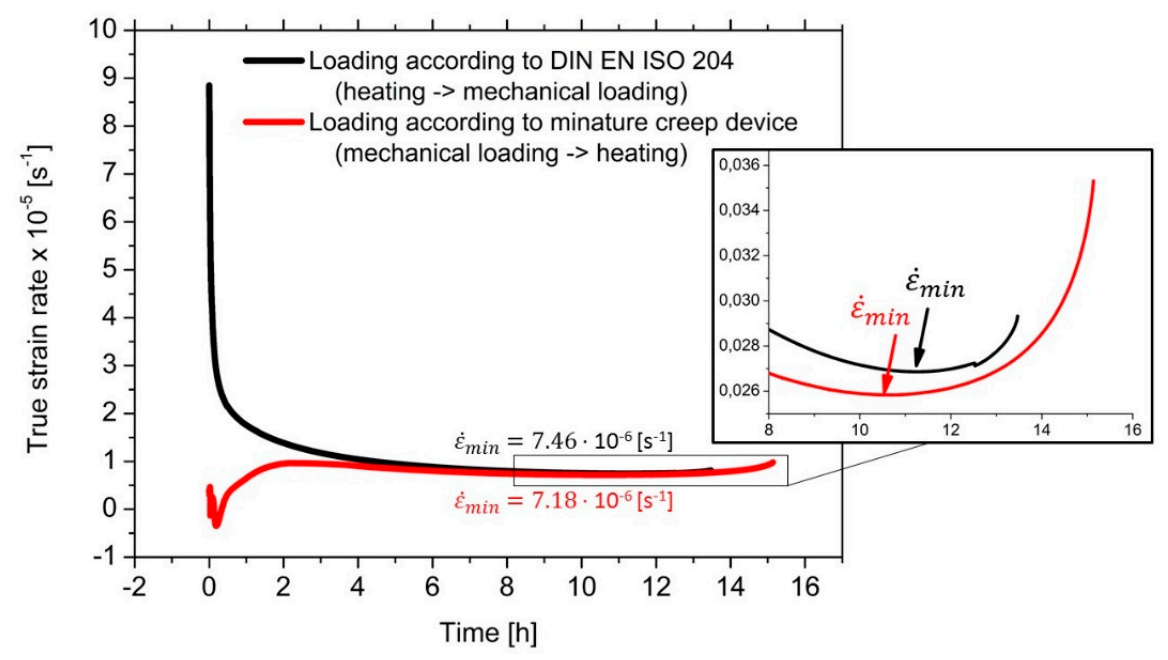

(b)

Figure 3. Comparison of different creep test procedures; (a) entire creep curves and detail of the very early primary creep stage, (b) entire curves of strain rate and detail of the region around minimum creep strain until fracture. 
The obtained creep parameters of the preliminary experiments are shown in Table 3. Based on the procedure described in [46], the error limits are estimated at about approximately $45 \%$.

Table 3. Creep parameters of preliminary creep tests.

\begin{tabular}{cccc}
\hline Test Procedure & $\begin{array}{c}\dot{\varepsilon}_{\text {min }} \\
\left(\mathbf{s}^{-1}\right)\end{array}$ & $\begin{array}{c}\varepsilon_{f r} \\
(-)\end{array}$ & $\begin{array}{c}t_{f r} \\
(\mathbf{h})\end{array}$ \\
\hline $\begin{array}{c}\text { Standard } \\
\text { (Heating } \rightarrow \text { mechanical loading) }\end{array}$ & $7.46 \times 10^{-6} \pm 3.36 \times 10^{-7}$ & $0.395 \pm 0.178$ & $13.5 \pm 6.075$ \\
$\begin{array}{c}\text { Variation due to miniature device } \\
\text { (Mechanical loading } \rightarrow \text { heating) }\end{array}$ & $7.18 \times 10^{-6} \pm 3.23 \times 10^{-7}$ & $0.537 \pm 0.242$ & $14.9 \pm 6.705$ \\
\hline
\end{tabular}

In comparison from Table 3 , it can be derived a slightly faster minimum creep strain rate $\dot{\varepsilon}_{\text {min }}$ leads to a shorter time to fracture $t_{f r}$ as well as a smaller creep strain at fracture $\varepsilon_{f r}$, whereas the slower minimum creep rate $\dot{\varepsilon}_{\text {min }}$ in contrast lead to a while longer creep lifetime $t_{f r}$ and higher creep strain at fracture $\varepsilon_{f r}$. Regarding the effect of a faster $\dot{\varepsilon}_{\text {min }}$ on $\varepsilon_{f r}$, this finding is not compliant to the literature, e.g., [51-53]: based on experience, a higher $\dot{\varepsilon}_{\text {min }}$ should lead to higher $\varepsilon_{f r}$. However, the minimum creep rate of the standard test procedure is reached at a later point in time compared to the varied test procedure due to miniature creep device. Regarding to a lower $\varepsilon_{f r}$ this in turn is in accordance with the literature. It is known, the exact time to fracture $t_{f r}$ and elongation at creep rupture $\varepsilon_{f r}$ is strongly dependent on the local defect characteristics of the material, e.g., pores or cracks [53]. As these tests are performed only once without repetitions and the results agree pretty well, thus, a negligible influence of the test procedure on $\varepsilon_{f r}$ and $t_{f r}$ is assumed here. The varied creep test procedure of the miniature creep device is found to be suitable to standard specimen investigated in the DSM 6102 test rig.

\subsubsection{Comparative Creep Tests}

Comparative creep measurements (miniature and standard) are conducted applying the varied creep test procedure (mechanical load $\rightarrow$ heating). Due to the high values of the miniature specimens, the initial instantaneous strain in the very early primary creep stage is subtracted, so only the time-dependent true creep strain is plotted. Both the miniature creep specimens and the standard creep specimens show typical creep behavior, with a primary, secondary, and tertiary creep stage of the true creep curves $\varepsilon_{\text {true }}=\boldsymbol{f}(\boldsymbol{t})$ (Figure 4). At $\sigma=10 \mathrm{MPa}$ the creep experiments with miniature specimen are prematurely stopped at $\boldsymbol{t}_{c r}=255$ and $995 \mathrm{~h}$ due to expected very long $\boldsymbol{t}_{f r}$ (Figure $4 \mathrm{a}$ ). Although the creep curves and consequently the respective creep parameters of the miniature specimens at $\sigma=25 \mathrm{MPa}$ are very different the average values are calculated.

In general, with increasing stress on the specimens, an increasing slope of the secondary creep stage and a decreasing total creep time can be observed. Furthermore, for the same test parameters, longer times to fracture $t_{f r}$ and a lower creep rate $\dot{\varepsilon}_{\text {min }}$ of the miniature specimens compared to the standard specimens are determined. The creep parameters derived from the creep curves are shown in Table 4 . The ductility of the material expressed by the necking at fracture $\mathbf{Z}$ is determined by:

$$
Z=\frac{A_{0}-\left(\pi \cdot r_{1} \cdot r_{2}\right)}{A_{0}} \cdot 100 \%
$$

where $A_{0}$ is the initial cross-section area and $\boldsymbol{r}_{1}, \boldsymbol{r}_{2}$ are the semi-axes of elliptical fracture surfaces. The average value of the necking at fracture of the standard specimens $Z_{\text {stand }}=51 \%$ is twice that of the miniature specimens $Z_{\text {mini }}=25 \%$. The error limits of the standard specimens are estimated by $\pm 45 \%$ based on the procedure described in [46], whereas the error limits of the miniature specimens are calculated from the results of repeated creep experiments. 


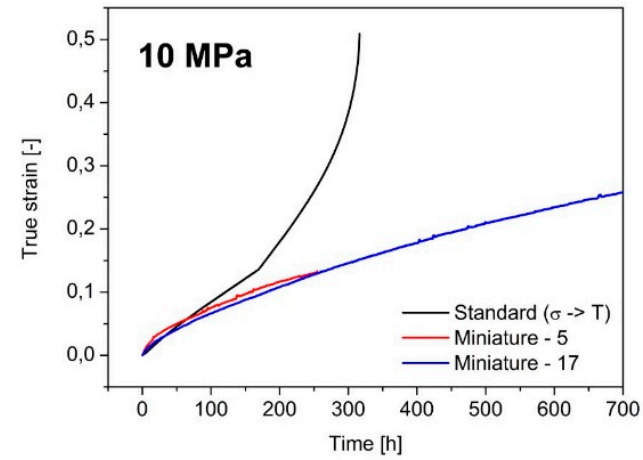

(a)

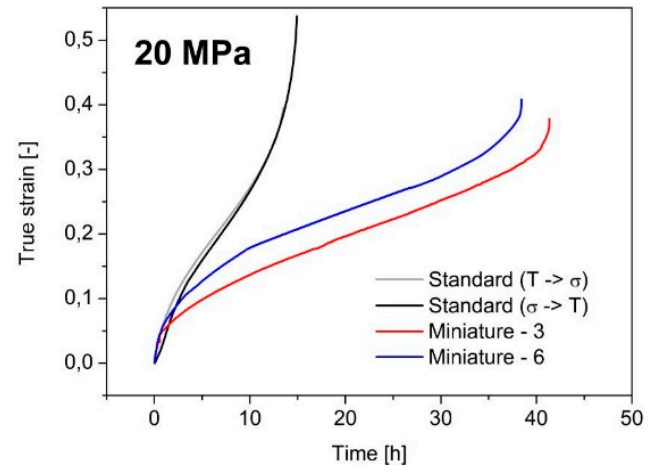

(c)

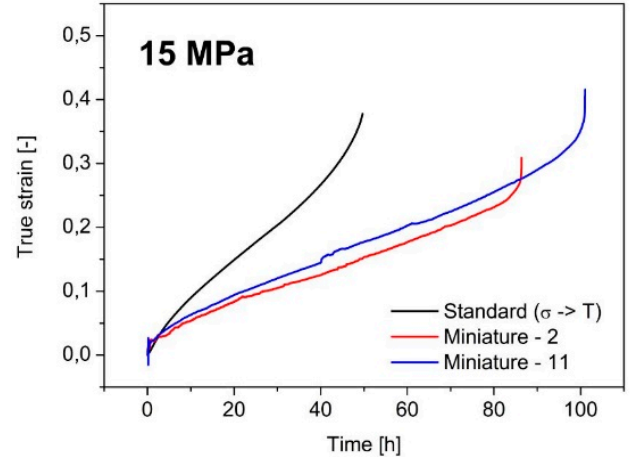

(b)

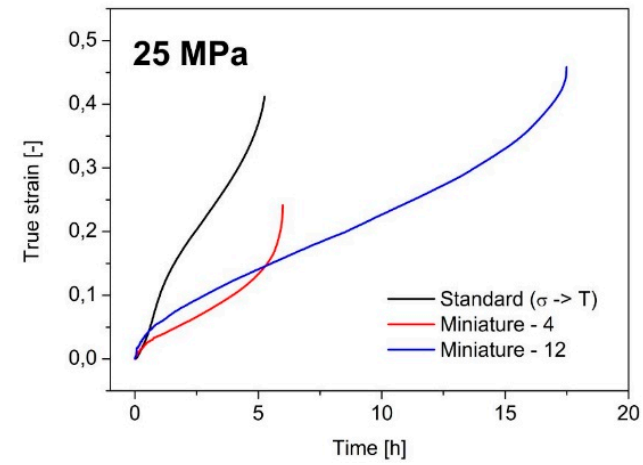

(d)

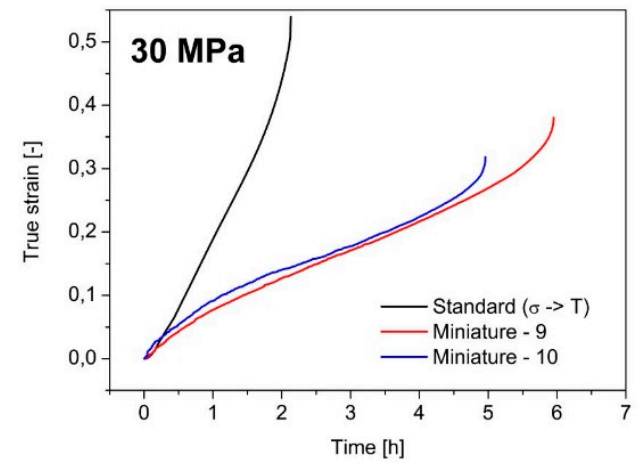

(e)

Figure 4. Creep curves, (a) $10 \mathrm{MPa}$, (b) $15 \mathrm{MPa}$, (c) $20 \mathrm{MPa}$, (d) $25 \mathrm{MPa}$, (e) $30 \mathrm{MPa}$.

\subsection{Microscopy}

$\mathrm{OM}$ of the standard and miniature specimen in the hot extruded and heat-treated condition after manufacturing is conducted in the region of the gauge length near the surface. Figure 5 shows the longitudinal sections of standard and miniature specimens not subjected to creep loading. Hence, the influence of the manufacturing process is shown. The region near the surface of the specimens manufactured by turning exhibits twinning due to deformation. As shown in Figure 5a, twinning of grains from the surface to a depth of $100 \mu \mathrm{m}$ is detectable in the standard samples with a diameter of $6 \mathrm{~mm}$. The grains of the miniature samples, on the other hand, are found to be twinned over the entire gauge volume diameter of $1 \mathrm{~mm}$. The twinning density gradually decreases from the surface to the center of the sample (Figure 5b). Moreover, a lower twinning density is observed outside the gauge volume (Figure $5 \mathrm{c}$ ). It should be noted that a strong scatter is observed within a miniature specimen batch regarding the degree of twinning. Some samples indicate a low twinning density, whereas other samples indicate a high twinning density. 
Table 4. Creep parameters of all investigated samples.

\begin{tabular}{|c|c|c|c|c|}
\hline \multicolumn{5}{|c|}{ Standard } \\
\hline $\begin{array}{c}\sigma \\
(\mathbf{M P a})\end{array}$ & $\begin{array}{l}\dot{\varepsilon}_{\min } \\
\left(\mathrm{s}^{-1}\right)\end{array}$ & $\begin{array}{l}\varepsilon_{f r} \\
(-)\end{array}$ & $\begin{array}{l}t_{f r} \\
\text { (h) }\end{array}$ & $\begin{array}{c}Z \\
(\%)\end{array}$ \\
\hline 10 & $1.89 \cdot 10^{-7} \pm 8.505 \cdot 10^{-8}$ & $0.507 \pm 0.228$ & $464.16 \pm 208.87$ & $54 \pm 2$ \\
\hline 15 & $1.41 \cdot 10^{-6} \pm 6.345 \cdot 10^{-7}$ & $0.378 \pm 0.17$ & $50.03 \pm 22.51$ & $50 \pm 1$ \\
\hline 20 & $5.99 \cdot 10^{-6} \pm 2.7 \cdot 10^{-6}$ & $0.535 \pm 0.241$ & $15.14 \pm 6.81$ & $50 \pm 2$ \\
\hline 25 & $1.49 \cdot 10^{-5} \pm 6.705 \cdot 10^{-6}$ & $0.411 \pm 0.185$ & $5.47 \pm 2.46$ & - \\
\hline 30 & $5.90 \cdot 10^{-5} \pm 2.655 \cdot 10^{-5}$ & $0.507 \pm 0.228$ & $2.31 \pm 1.04$ & $51 \pm 2$ \\
\hline \multicolumn{5}{|c|}{ Miniature } \\
\hline $\begin{array}{c}\sigma \\
\text { (MPa) }\end{array}$ & $\begin{array}{c}\dot{\varepsilon}_{\min } \\
\left(\mathrm{s}^{-1}\right)\end{array}$ & $\begin{array}{c}\varepsilon_{f r} \\
(-)\end{array}$ & $\begin{array}{l}t_{f r} \\
\text { (h) }\end{array}$ & $\begin{array}{c}Z \\
(\%)\end{array}$ \\
\hline 10 & $5.59 \cdot 10^{-8} \pm 1.3 \cdot 10^{-8}$ & - & - & - \\
\hline 15 & $5.09 \cdot 10^{-7} \pm 9.0 \cdot 10^{-9}$ & $0.487 \pm 0.048$ & $94.17 \pm 7.35$ & $27 \pm 3$ \\
\hline 20 & $1.47 \cdot 10^{-6} \pm 6.0 \cdot 10^{-8}$ & $0.558 \pm 0.29$ & $41.84 \pm 29.47$ & $26 \pm 4$ \\
\hline 25 & $4.56 \cdot 10^{-6} \pm 3.4 \cdot 10^{-7}$ & $0.457 \pm 0.177$ & $12.16 \pm 5.77$ & - \\
\hline 30 & $1.09 \cdot 10^{-5} \pm 8.5 \cdot 10^{-7}$ & $0.472 \pm 0.019$ & $5.86 \pm 0.50$ & $26 \pm 5$ \\
\hline 35 & $3.49 \cdot 10^{-5} \pm 1.57 \cdot 10^{-5}$ & $0.402 \pm 0.181$ & $1.38 \pm 0.80$ & $4 \pm 0.5$ \\
\hline
\end{tabular}
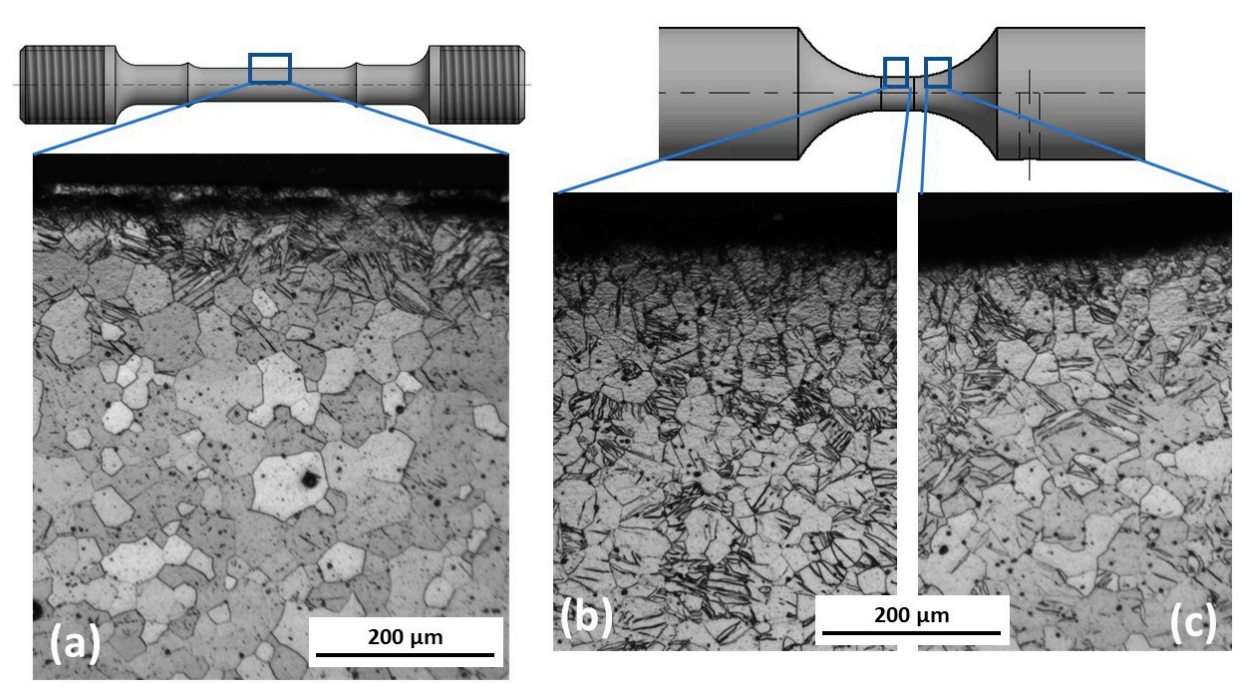

Figure 5. OM of the microstructure, longitudinal section, near-surface region, (a) standard specimen, (b) miniature specimen in the gauge length, (c) miniature specimen beyond the gauge length.

The microstructure of the standard and miniature samples after the creep experiments are also investigated. The observations described below occur in both the standard and the miniature specimens, although with different dimensions. First, the focus is on changes of the grain morphology: increasing mechanical stress is observed to be accompanied by increasing elongation of the grains. Starting from nearly globular grains $($ ratio $=1.0)$ at $\sigma=10 \mathrm{MPa}$, several of which at this load have twins, the aspect ratio is developing to $1.5(\sigma=15 \mathrm{MPa}), 1.8(\sigma=20 \mathrm{MPa})$ to a maximum of $1.9(\sigma=30 \mathrm{MPa})$ illustrated exemplary on the standard specimen (Figure 6). The values of the aspect ratios are shown in Table 5. 


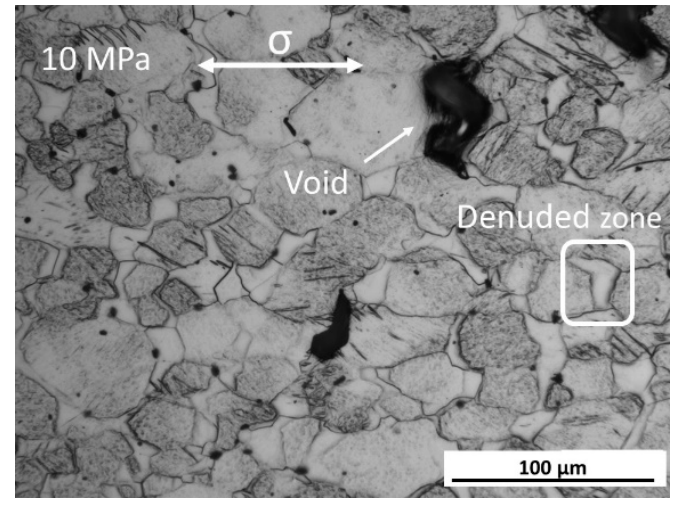

(a)

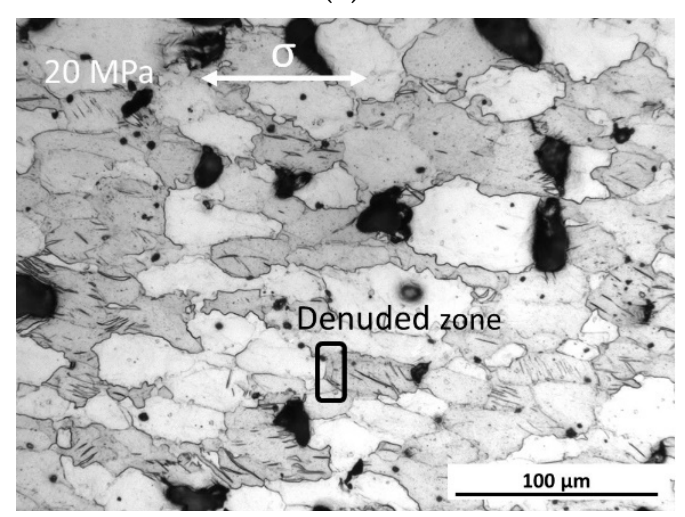

(c)

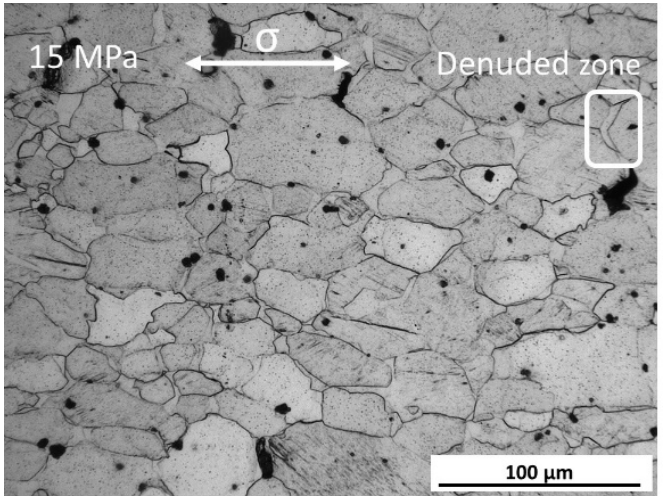

(b)

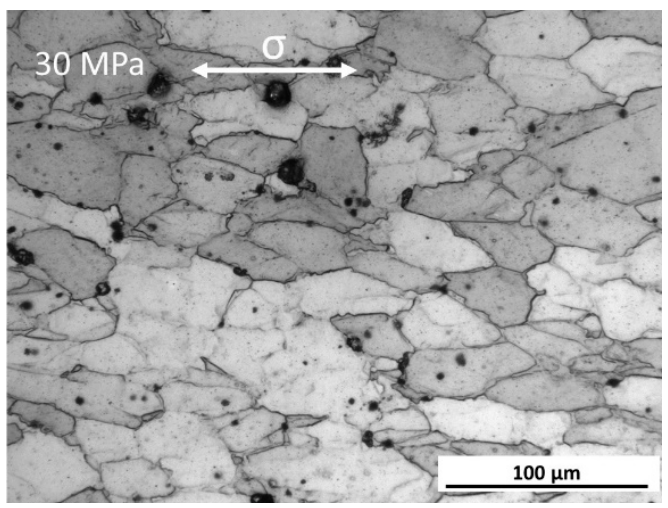

(d)

Figure 6. Longitudinal sections of crept standard samples, microstructure at different mechanical loads, (a) $10 \mathrm{MPa}$, (b) $15 \mathrm{MPa}$, (c) $20 \mathrm{MPa}$, (d) $30 \mathrm{MPa}$.

Table 5. Aspect ratios of elongated grains.

\begin{tabular}{cccccc}
\hline & $\mathbf{1 0} \mathbf{M P a}$ & $\mathbf{1 5} \mathbf{~ M P a}$ & $\mathbf{2 0} \mathbf{M P a}$ & $\mathbf{2 5} \mathbf{~ M P a}$ & $\mathbf{3 0} \mathbf{~ M P a}$ \\
\hline Standard & 1 & 1.5 & 1.8 & 1.8 & 1.9 \\
Miniature & 1 & 1.1 & 1.2 & 1.3 & 1.4 \\
\hline
\end{tabular}

In addition, denuded zones-known from creep experiments on, for example, $\mathrm{Zr}$ containing Mg-alloys, e.g., [54-57]—are detected at the grain boundaries oriented perpendicular to the loading direction, the size of which is dependent on load and thus from the creep time. As higher the load, as smaller the denuded zones. While in the standard specimens at $\sigma=10 \mathrm{MPa}$, the width of the denuded zones $w_{d Z}, 10 M P A$ is approx. 8 to $10 \mu \mathrm{m}$ (Figure 6a), at $\sigma=20 \mathrm{MPa}$ the width $w_{d \mathrm{Z}, 20 \mathrm{MPA}}$ is approximately 1 to $2 \mu \mathrm{m}$ (Figure 6c), whereas at $\sigma=30 \mathrm{MPa}$ denuded zones are not observed (Figure $6 \mathrm{~d}$ ). In the miniature

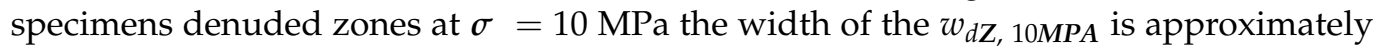
$6 \mu \mathrm{m}$. Here, the zones are detectable up to $\sigma=20 \mathrm{MPa}$.

Further investigations on the denuded zones are carried out by SE imaging and EDS measurements analyzing the structure and chemical composition. Due to large, denuded zones, the measurements were performed on a standard specimen loaded at $\sigma=10 \mathrm{MPa}$. Different grey values in the SE image already indicate an inhomogeneous distribution of the elements (Figure 7a). A pile-up of Mn-particles at grain boundaries parallel to the loading axis is detected (red arrow). An EDS mapping illustrates a depletion of the alloying element manganese in the denuded zone (Figure 7b) qualitatively. Quantitatively EDS single point measurements verify that the Mn concentration in the denuded zone is about 0.1 at $\%$, whereas in the grains 0.8 at $\%$ to 0.9 at $\%$ are measured. Therefore, EDS line scans parallel to loading direction are conducted, showing in the adjacent grains (left and right) to the denuded zones that the Mn concentration and distribution are different. According to the line scan shown in 
Figure $7 \mathrm{c}$ in the grain on the left from point (1), the Mn concentration is constant at an average of approx. $0.8 \mathrm{at} \%$. Between the points (1) and (2) - the denuded zone-the Mn concentration drops to zero. To the right of point (2), there is a continuous increase in the Mn concentration, which initially fluctuates around an average of $2.5 \mathrm{at} \%$, abruptly dropping back to the already known approx. 0.8 at\%. The area around point (3) is enriched by Mn-precipitates marked with arrows in the SE image (Figure $7 \mathrm{c}$, left side), explaining the concentration fluctuations around a mean value. The different Mn concentrations in the respective areas are assumed to be due to a directional diffusion of Mn.

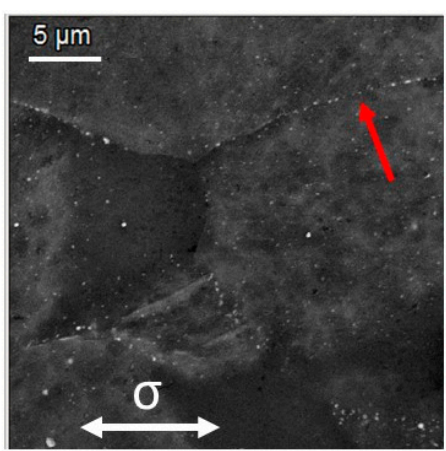

(a)

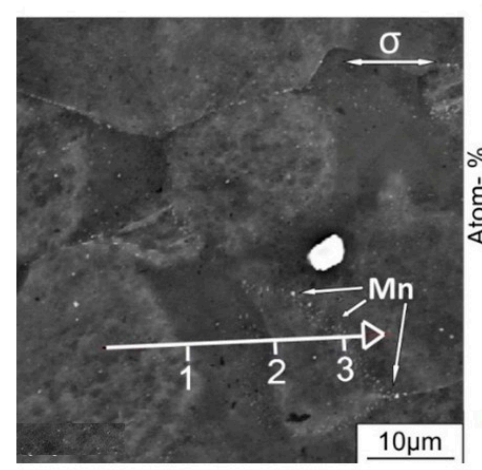

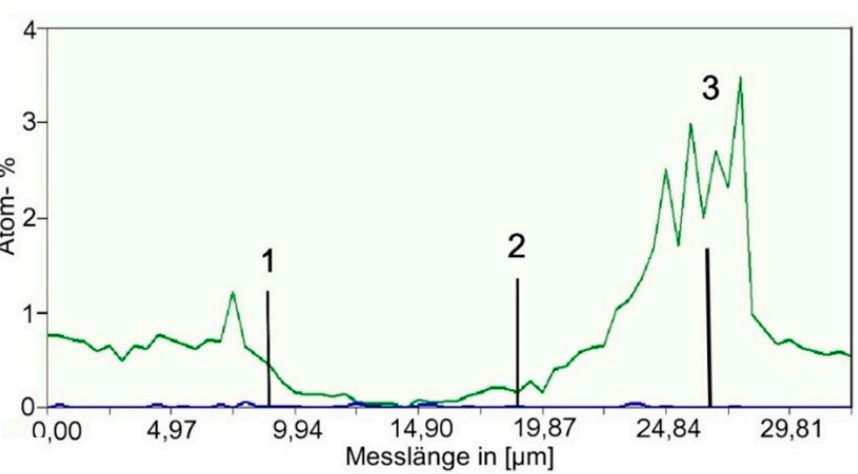

(c)
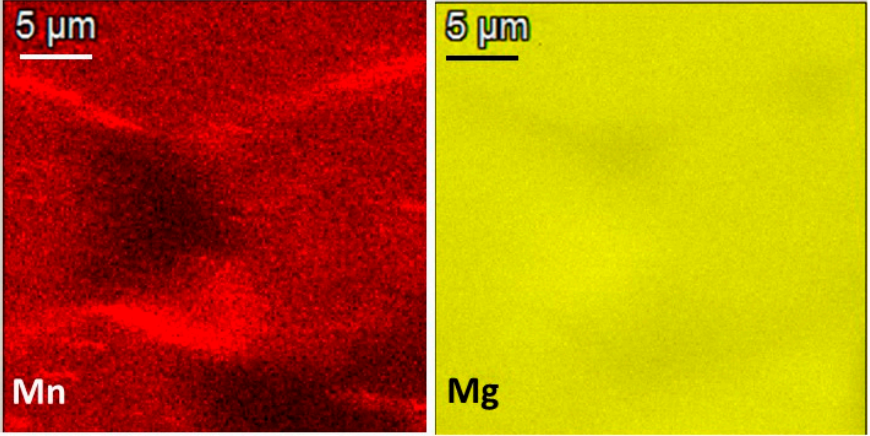

(b)

Figure 7. SEM, denuded zone, (a) SE image, (b) EDX-mapping of Mn + Mg, (c) EDS-line scan.

Additionally to the grain morphology and the denuded zones, the creep voids are characterized by shape and distribution. It has to be noticed, detailed analysis of the porosity fraction is not the subject of this work. The creep voids form preferentially at grain boundaries oriented perpendicular to the loading direction (Figure 6). Figure 8a-c show the longitudinal sections of a standard creep specimen at $\sigma=20 \mathrm{MPa}$. Next to the fracture surface a higher porosity is observed (Figure 8a). As already visually is apparent, with increasing distance from the fracture surface, a gradual decrease in void number and size occurs (Figure $8 \mathrm{a}-\mathrm{c}$ ). This behavior is detected in all measured specimens and thus appears to be independent of load. The shape of individual voids is predominantly elliptical, with the longitudinal axis oriented perpendicular to the loading direction. The same behavior is observed in the miniature creep samples, too (Figure $8 \mathrm{~d}$ ). 

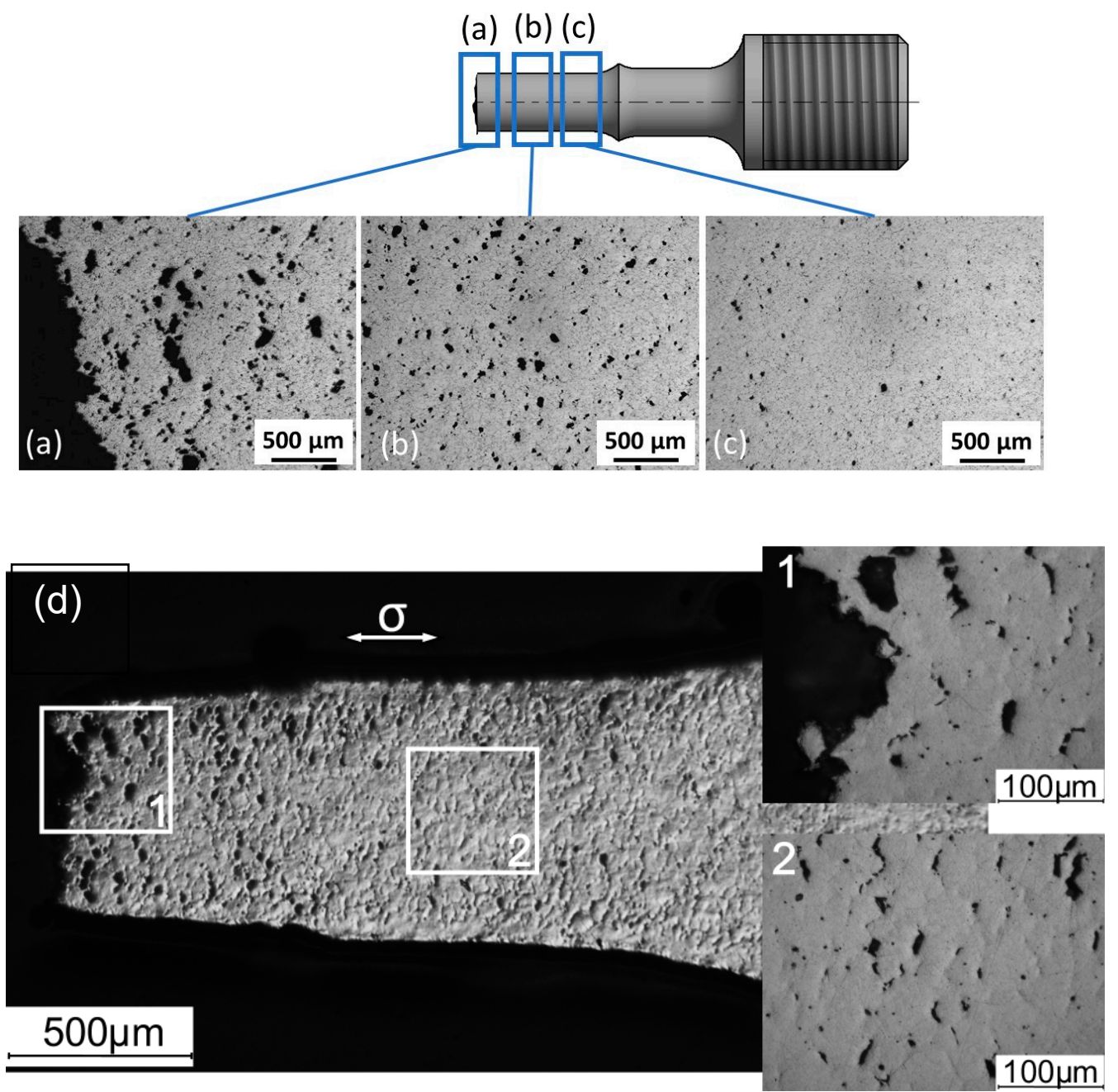

Figure 8. Creep damage, $20 \mathrm{MPa}$, longitudinal section; (a-c) standard specimen, (a) near fracture surface, (b) $5 \mathrm{~mm}$ distance to fracture surface, (c) $10 \mathrm{~mm}$ distance to fracture surface; (d) miniature specimen.

\section{Discussion}

\subsection{Validation of Creep Experiments}

As only a few experiments, the creep test using standard geometries merely once and with miniature specimens only one repetition test each, are performed the plausibility of the individual creep experiments is verified using the modified Monkman-Grant relationship [58]:

$$
t_{f r}=\frac{\mathrm{C} / \varepsilon_{f r}}{\dot{\varepsilon}_{\min }^{m \prime}}
$$

The ratio $\varepsilon_{f r} / t_{f r}$ is plotted against $\dot{\varepsilon}_{\text {min }}$ in double logarithmic scale (Figure 9). Here, according to [58] the exponent $m$ ' is proven and found to be 1 . The error limits of the standard specimen tests are estimated from the error limits calculated by the test repetitions of the miniature creep experiments. 


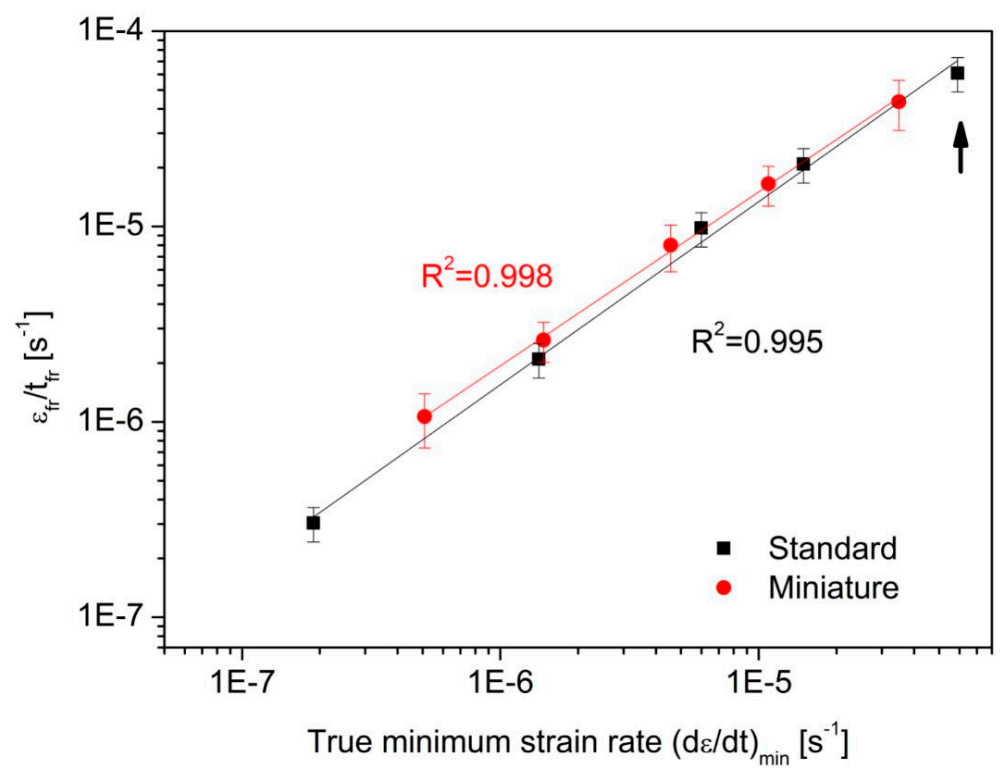

Figure 9. Illustration of the modified Monkman-Grant equation.

For both the standard and the miniature creep tests, a linear relationship can be determined for the individual measuring points using a regression coefficient $R^{2}$. The coefficients $\boldsymbol{R}^{2}=0.995$ for the standard specimens and $\boldsymbol{R}^{2}=0.998$ for the miniature specimens are observed. Thus, the validity of the individual tests is demonstrated, although, for the standard experiments, no repetitions are carried out. This is particularly relevant for validating the result of the creep test with standard geometry at $\sigma=30 \mathrm{MPa}$, marked by an arrow in Figure 9. As the value of $\dot{\varepsilon}_{\min }=5.9 \times 10^{-5} \mathrm{~s}^{-1}$ is slightly above the theoretical limit of creep tests of $\dot{\varepsilon}_{\min }=5.0 \times 10^{-5} \mathrm{~s}^{-1}$, according to Maier identifying the transition to the power-law-breakdown [53]. However, due to the sufficiently accurate position on the regression line, the test can be used to characterize the creep behavior and determine the Norton stress exponent (cf. Section 4.3).

\subsection{Test Procedure}

As the sequence of the creep test procedure of the miniature creep device due to its design is not variable, the applicability to the standard specimen in a commercial test rig is validated. The force application is different in both test rigs, in the miniature device by spring and in the DSM 6102 test rig by an electric motor. The latter ensures constant force application to the specimen throughout the test. However, in the miniature creep device, the spring expands according to the elongation of the specimen. As a result, the loading force decreases proportionally to the specimen strain, while at the same time, the cross-section of the specimen is reduced. For low creep strains $\varepsilon<0.4$, a change in mechanical loading of $5 \%$ is calculated. Consequently, the expansion of the spring can be neglected so that the assumption of force constancy can be justified (cf. [46]).

The change in the sequence of mechanical and thermal load application compared to the standard test procedure compliant to DIN EN ISO 204 in the varied test procedure according to the miniature device in the primary stage of the creep curve an untypical behavior occurs (cf. Figure 3). Plotting the curves of the creep strain and the creep rate in comparison to the specimen temperature, the atypical behavior in the primary creep stage is illustrated (Figure 10). It is found that the behavior of the strain and strain rate curve within the first quarter of an hour in all tested specimens independent from the mechanical load is the same. However, the characteristic of the curves depends on the amount of the mechanical load. It is assumed that in the very early primary creep stage, the strain and strain rate is essentially determined by the heating-up process than by time-dependent plastic deformation as described by Weertman [59,60], Cottrell [61], and the literature $[53,62]$. The investigation of the detailed microstructural processes at this 
stage is not the subject of this work. At the latest, when the test temperature and thermal equilibrium are reached, the strain and strain rate curves follow the typical creep curve shapes (cf. Figure 3), which is in good agreement with $[10,12,46]$. From this, it can be concluded, in the varied creep test procedure already in the later primary creep stage, the known hardening and softening mechanisms of the creep process correspond to those in the standard test procedure according to DIN EN ISO 204.

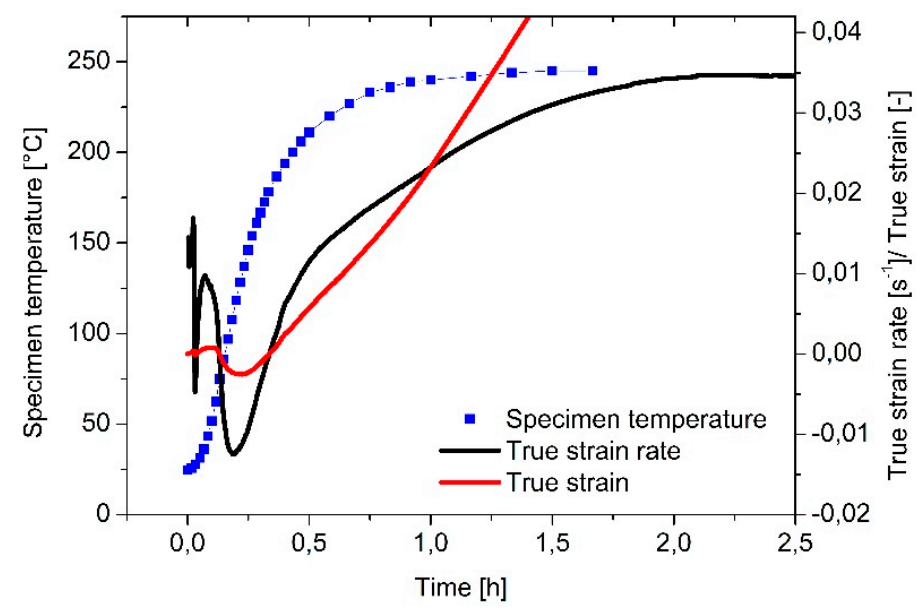

Figure 10. Comparison of the curves of true strain, true strain rate, and specimen temperature in the early primary creep stage.

\subsection{Creep Behavior}

The creep parameters (cf. Table 4 ) of the miniature and standard geometry experiments taken from the true strain and true strain rate curves show differences: for the miniature specimens $\varepsilon_{f r}$ and $\dot{\varepsilon}_{\text {min }}$ are shifted to lower values, $t_{f r}$ is higher by a factor of about 2 to 2.5 , the proportion of the secondary creep stage of the total creep curve is percentual higher, and $Z$ only half compared to the creep experiments with the standard specimen (Figure 11). Analyzing the creep parameters in detail, the true strain at fracture $\varepsilon_{f r}$ for the standard specimens indicate no dependency from the mechanical stress. In contrast $\varepsilon_{f r}$ of the miniature specimen within the error limits decreases with increasing stress (Figure 11a). The latter behavior is also known from the literature [52,53,62]. However, due to the small number of experiments - the standard experiments are carried out once, and the miniature experiments twice for each stress loading - the error limits are taken as an average from all miniature creep experiments are high. However, as it can be derived from Figure $4 \mathrm{~d}$ in a single case, the difference can be much higher. As repeating measurements of standard specimens are missing here, qualitatively, the tendency to lower values of $\varepsilon_{f r}$ as a function of $\sigma$ for the miniature compared to the standard specimens can be determined, but a quantification is not possible. Furthermore, lower strain rate values $\dot{\varepsilon}_{\text {min }}$ for the miniature compared to the standard specimens are obtained. From the minimum strain rate values the Norton-exponent is determined verifying the creep mechanisms taking place (Figure 11b). A parallel shift of the Norton line to lower creep rates for the miniature specimens occurs. However, within the error limits, the value of the Norton-exponent is the same for both the miniature creep experiments $n_{\text {mini }}=4.9 \pm 0.2$ and the standard creep experiments $n_{\text {standard }}=5.1 \pm 0.2$. Hence, a value of the Norton-exponents of approximately 5 indicates the creep mechanism of dislocation creep for both specimen geometries. The creep diagram in the double-logarithmic scale reveals a linear relationship of $\sigma$ and $t_{f r}$ holding the same power $(-0.21)$ independent from the specimen geometry (Figure 11c). A parallel shift of the correlation line to higher values of the miniature specimens is observed here. 


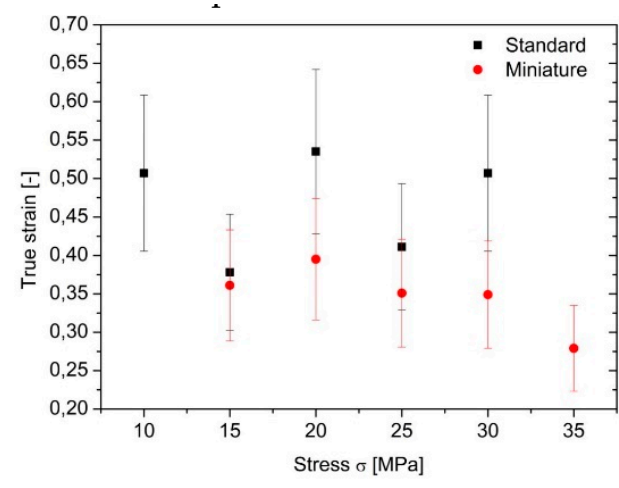

(a)

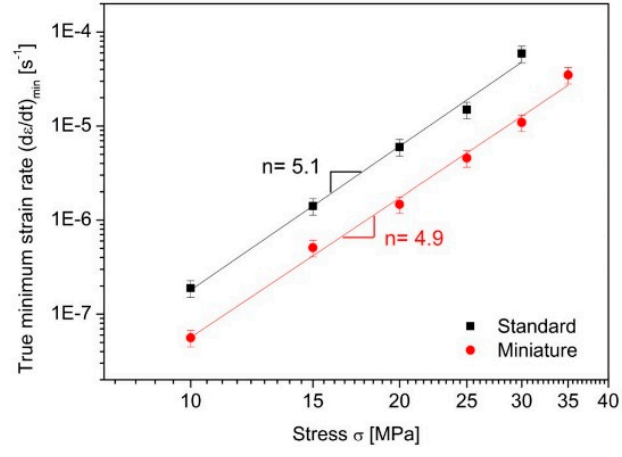

(b)

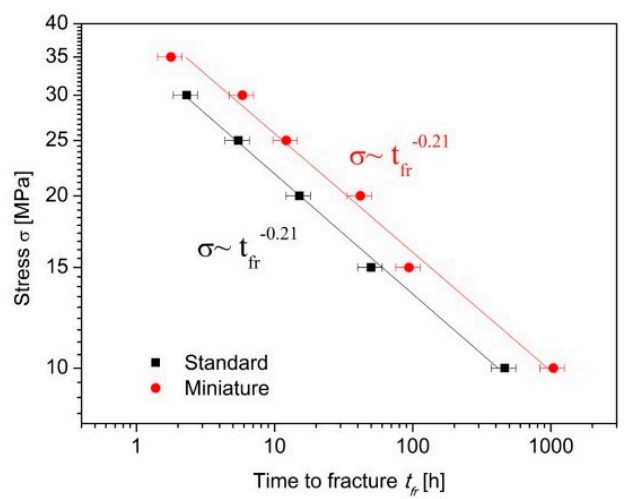

(c)

Figure 11. Creep parameter, (a) strain at fracture, (b) Norton-exponent, (c) creep diagram.

Lower $\varepsilon_{f r}$ and $\dot{\varepsilon}_{\text {min }}$, higher $t_{f r}$, shifting of the Norton line and curve of creep rupture strength to higher values and lower $Z$ indicate a higher creep resistance of the miniature specimens than standard specimens. The mechanisms behind, are discussed in the following section.

\subsection{Creep Mechanisms}

As shown in Section 4.3, the creep parameters determined by miniature experiments are not arbitrarily different from the determined creep parameters of the standard specimens but have systematic differences. This is taken from parallel shifts of the Norton line to lower creep rates and the creep rupture strength to higher values for the miniature specimens. While in the work of Kurumlu et al. [10,11] and Mälzer et al. [12], no size dependence of creep parameter of miniature and standard specimens is found, on the other hand nevertheless this is described by Olbricht et al. [9], Krompholz et al. [63], Schmieder [64], Camin [46], and Dymácek et al. [65]. Altogether, the results are inconsistent. In [46], the same miniature creep device as in this work was used. Consequently, the specimen dimensions and test procedure are the same; however, the heating in [46] was faster. As well as here, in [46], systematic deviation of the miniature creep experiments compared to standard experiments is determined from the values from the literature [66]. Nevertheless, different from here, the minimum creep rates of the miniature experiments show higher values. In [46], the creep behavior of metal matrix composites (MMC) materials was investigated in situ during creep by $\mu$-tomography at the ESRF. An influence of the material can be excluded since $[10,11]$ investigated the same class of material, obtaining contrary results. However, certainly miniaturized flat tensile specimens exhibiting a ratio of $l_{0} / d_{0} \approx 6$ were used by $[10,11]$, whereas [46] used miniaturized cylindrical specimens with a ratio of $\boldsymbol{l}_{0} / d_{0}=1$. Cao et al. compared flat and mild notched cylindrical specimens under uniaxial load [67]. The notched cylindrical specimens with dimensions very similar to the specimens used in this work and [46] exhibited less strain than the flat samples [67], as observed here also. Cao et al. attributed this behavior to multiaxial stress states occurring 
in the notch. A multiaxial stress state in the miniature specimens used here may be one explanation for the higher creep resistance measured here. Furthermore, based on FEM results, Cao et al. concluded that unavoidable inaccuracies in manufacturing the miniature round notch specimens could be tolerated because only a minor influence $(\approx 5 \%)$ on the stress parameters characterizing the multiaxial stress states was found. This may apply to manufacturing tolerances, but not to changes in microstructure due to manufacturing, e.g., twins, as detected in this work and discussed below. Twinned grains and dislocations induced by cold working during manufacturing are beneficial for creep resistance interfering with dislocation movement.

The microstructural aspect has already been studied in other works. In ASTM E139 [8], it is assumed that specimen size effects expected to specimen miniaturization can be explained by the small number of grains in the specimen volume resulting in a higher impact of each individual grain orientation. This was investigated by Krompholz et al. using cylindrical specimens of different sizes. The creep parameters achieved, additionally to size effects, show unsystematic dependencies due to the test temperature and stress [63]. Krompholz et al. suggest that the diffusion processes, decisive for creep, are higher weighting in miniaturized specimens than in standard specimens, leading to differences in the creep parameters. Olbricht et al. in [9] criticized the latter interpretation of Krompholz et al. As it is elusive which diffusion process could be responsible for this.

Consequently, by combining the results from $[9-11,46,63,67]$ and this work as interim results, it can be noted that not only the geometry of the miniature samples influences the systematic shift of the creep parameters measured here. As the effect of faster heating was not investigated in this work, the possible effect cannot be evaluated. Thus, comparative miniature creep experiments to standard geometries allow a qualitative characterization of the creep behavior due to the systematic deviations. In contrast, a direct comparison of quantitative parameters is not possible without knowledge and explanation of the reasons for the systematic deviation.

Hence, within this work's scope, comparative microstructural investigations of noncreep-stressed and creep-stressed miniature and standard specimens are carried out. After sample manufacturing, a significantly higher number of twins are detected in the miniature creep specimens $(\varnothing 1 \mathrm{~mm})$ than in the specimens with standard geometry $(\varnothing 6 \mathrm{~mm})$ due to higher stress by the centering mandrel and the machining, since the forces affecting a smaller cross-sectional area (cf. Figure 5). The observation of an increased number of twinned grains in the miniature specimens is therefore relevant, because in the work of Randle [68] and Alexandreanu et al. [69] in the context of "grain-boundary-engineering" an indirect influence of twins on material properties such as corrosion, ductility and creep strength are assumed. While Randle mentioned an influence by $\Sigma 3$ oriented Coincidence Site Lattice (CSL) grain boundaries (twins) on creep properties in cubic materials, the studies of Alexandreanu et al. validating the Thaveeprungsriporn model [70] indicate that a reduced creep rate can be observed at increased Coincidence Site Lattice Boundary (CSLB) fractions in cubic crystal systems. These findings support the results of this work.

Furthermore, the microstructural investigations reveal a systematically increased necking at fracture $\boldsymbol{Z}$ by a factor of 2 for the creep-stressed standard compared to miniature specimens. The fracture necking attributed to the ductility of the material is strongly dependent on creep damage. Elliptical pores are formed at grain boundaries oriented perpendicular to the loading axis (cf. Figures 6 and 8). According to Cocks and Ashby [71], this is evidence of void growth by surface diffusion. As these voids act as small cracks, the damage in the miniature specimens due to their small size must be weighted more than in the standard specimen. This can explain the low fracture necking.

The stress-dependent Norton-exponent $\boldsymbol{n}=5$ indicating plastic deformation is typically associated with dislocation creep (cf. Section 4.3). Additionally, grain elongation oriented parallel to the load can be seen in the optical micrographs. This grain elongation can be explained by both plastic deformations due to dislocation movements and diffusion processes. According to Rösler et al. [52] and Kassner [72], increased concentration of 
vacancies can be expected at grain boundaries oriented perpendicular to the load. As a result, a mass flow occurs in the direction of the tensile load, causing a grain shape change, which is also detected here.

Furthermore, at lower loads $\sigma \leq 20 \mathrm{MPa}$, denuded zones at grain boundaries oriented perpendicular to the load are observed (cf. Figure 7). In the past, many creep experiments on Mg-alloys containing the alloying element Zr were carried out investigating this phenomenon. However, the mechanisms behind are discussed widely and differently, e.g., in [54-57,73-75]. Squires et al. [54] observed a similar characteristic of zircon (Zr) depleted regions in Mg-0.5 wt \% $\mathrm{Zr}$ alloys as detected here (cf. Figure 7). The authors attributed this to preferential magnesium bulk diffusion in the load direction. Studies by Burton and Reynolds [76], as well as Greenwood [74], Owen et al. [77], and Langdon [73] indicate that alloy element denuded zones are indicative for diffusion creep. Langdon describes the accompanied pile-up of particles at grain boundaries (cf. Figure 7a) and elongation of the grains (Figure 6) parallel to the loading axis, both observed here also, as attributed to diffusional creep. However, a Norton-exponent $\boldsymbol{n}=1$ related to diffusional creep is specified in [73], different from $n=5$ related to dislocation creep found in this work. In [76] it is further discussed that grain boundaries are often not centrally located in the denuded zone, which would be expected assuming an equal flow of material from both adjacent grains toward the grain boundary. Burton and Reynolds attribute this to increased mobility of grain boundaries in diffusion zones responding to minor external disturbance by moving to the end of the denuded zone. Wolfenstine et al., however, refuted the relationship between denuded zones and diffusional creep [56]. Kloc, in turn, refers to the work of Wolfenstine et al., and in contradiction to this, it is argued that a unilateral occurrence of a denuded zone is entirely compatible with the theory of diffusion creep. However, it is justified to the asymmetry of the random grain boundaries [75]. Wadsworth et al. proposed a model for the formation of denuded zones and illustrated schematically the mechanisms behind. The mechanism postulated is grain boundary sliding rate-controlled by dislocation climb [57]. From their point of view, a simultaneous action of grain boundary sliding, and grain boundary migration are responsible for dissolving small particles, dragging of undissolved particles growing bigger as small particles dissolve, and diffusion of solute atoms. The SEM and EDS investigations presented in Figure 7 are supported by the proposed model of Wadsworth et al.: Due to uniaxial mechanical loading denuded zones are observed only at boundaries transverse to the tensile direction (Figure 12a, yellow arrow). The grain boundary is located between the denuded zone and a Mn-containing precipitate zone. The denuded zone introducing a fresh amorphous-like region is depleted of the alloying element Mn (Figure 12b,c, between red arrows). Undissolved Mn-precipitates are dragged by the migrating boundary (Figure 12b,c, yellow arrow and dashed line). Some larger particles brake away from the migrating boundary remaining in the denuded zone (Figure $12 b, c$, magenta arrow). Furthermore, on lateral grain boundaries precipitates occur due to diffusion of solute atoms, mentioned by [73] also (Figure 12b,c, green arrows).

The results of the microstructural investigations thus indicate that the plastic deformation of the coarse-grained ME21 creep specimens at $\sigma$ up to maximum $20 \mathrm{MPa}$ can be explained by dominating dislocation creep accompanied by a minor process of grain boundary sliding and migrating, whereas, at $\sigma>20 \mathrm{MPa}$, the plastic deformation is due to dislocation creep only.

Apart from a different number of twinned grains and different levels of fracture necking, on the observed scale, no microstructural differences can be found in the miniature and standard specimens. Consequently, in this work, the microstructural creep mechanisms activated in the material are independent of the specimen size. However, a decreased creep rate and increased creep rupture time indicate different kinetics of the mechanisms, which are not investigated in this work. 


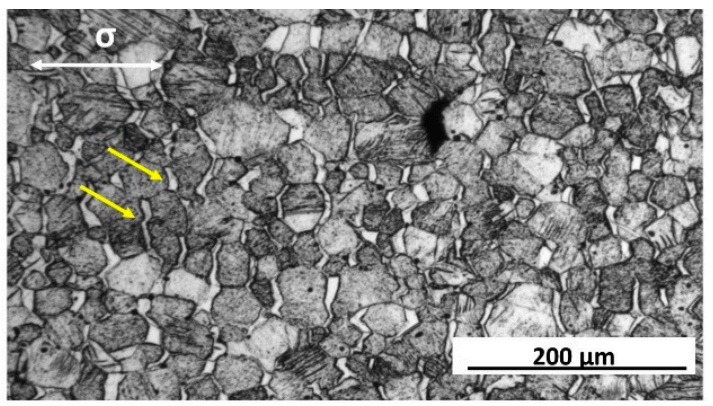

(a)

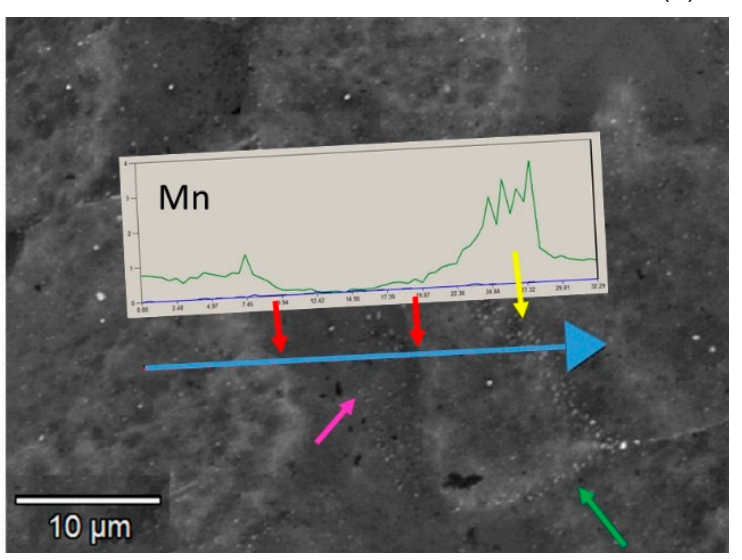

(b)

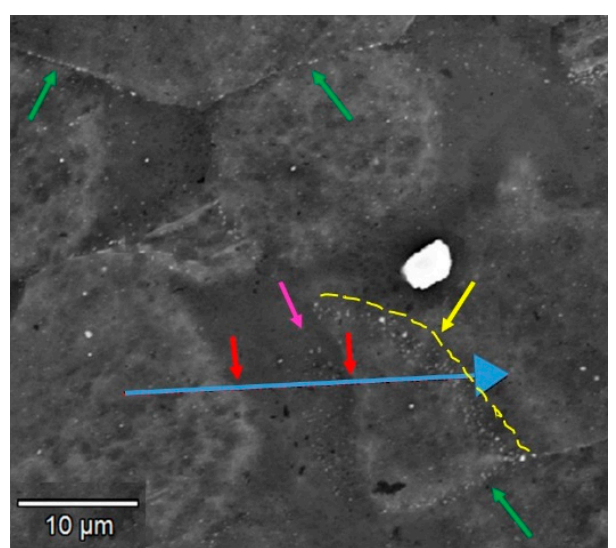

(c)

Figure 12. Microstructure after creep, $\sigma=10 \mathrm{MPa}$ : (a) OM, yellow arrows: denuded zones; (b,c) EDS measurements, blue arrow indicates the line scan, Mn depleted zones between red arrows, yellow dashed line: migration grain boundary, yellow arrow: undissolved Mn-precipitates, magenta arrow: large Mn-particles, green arrows: Mn-precipitates on grain boundaries.

\section{Conclusion}

Comparative uniaxial creep measurements on miniature and standard specimens of different geometries on hot extruded and heat treated ME21 magnesium alloy are performed according to the test procedure of a miniature creep device initially developed for in situ XCT experiments. The sequence of loading of the test procedure (mechanical load $\rightarrow$ heating) different from the standard creep test (heating $\rightarrow$ mechanical loading) lead to a different creep behavior in the very early primary creep stage. However, the higher initial creep strain of the miniature samples is associated with the miniature creep device and does not affect the entire creep behavior. Overall, in all experiments-miniature and standard-a typical primary, secondary, and tertiary creep behavior are observed. Hence, the applicated test procedure provides reliable results.

The main creep mechanism is identified as dislocation creep, at lower stresses accompanied by grain boundary sliding and migrating of minor influence, occurring identically in both specimen geometries and, thus, is independent of specimen size.

However, the analyses of the creep parameters detect a higher creep resistance for the miniature creep specimens. A higher number of twinned grains originated by the manufacturing process indicates a higher work hardening interfering with the dislocation movement, being beneficial for creep resistance. Therefore, it can be assumed, a higher fraction of twinned grains within the gauge volume gains more importance in small specimens. In addition, in a notch-like gauge volume of the miniature specimens, an emerging multiaxial stress state is possible. Therefore, the higher creep resistance of the miniature specimens measured here is probably dependent on both the twinned grains and geometry in the gauge volume. In a good approximation, the creep behavior of a material can be determined by miniature creep specimens; however, a direct comparison of quantitative creep parameters is not possible without the knowledge and explanation of the reasons for systematic deviations. 
Author Contributions: Conceptualization, B.C.; methodology, B.C.; validation, M.G.; formal analysis, B.C. and M.G.; investigation, B.C.; writing-original draft preparation, B.C. and M.G.; writingreview and editing, B.C. and M.G.; visualization, B.C. and M.G. All authors have read and agreed to the published version of the manuscript.

Funding: The publication of this article was funded by the Open Access publication fund of the Technische Universität Berlin.

Acknowledgments: We acknowledge support from the Open Access publication fund of the Technische Universität Berlin and the Extrusion Research and Development Center of the Technische Universität Berlin (FZS) for providing the material.

Conflicts of Interest: The authors declare no conflict of interest.

\section{References}

1. MacLeod, S.; Errandonea, D.; Cox, G.A.; Cynn, H.; Daisenberger, D.; Finnegan, S.; McMahon, M.; Munro, K.; Popescu, C.; Storm, C. The phase diagram of Ti-6Al-4V at high-pressures and high-temperatures. J. Phys. Condens. Matter 2021. [CrossRef]

2. Smith, D.; Joris, O.P.J.; Sankaran, A.; Weekes, H.E.; Bull, D.J.; Prior, T.J.; Dye, D.; Errandonea, D.; Proctor, J.E. On the high-pressure phase stability and elastic properties of $\beta$-titanium alloys. J. Phys. Condens. Matter 2017, 29, 155401. [CrossRef]

3. Dorward, R.C.; Pritchett, T.R. Advanced aluminium alloys for aircraft and aerospace applications. Mater. Des. 1988, 9, 63-69. [CrossRef]

4. Wang, G.G.; Bos, J. A study on joining magnesium alloy high pressure die casting components with thread forming fasteners. J. Magnes. Alloy. 2018, 6, 114-120. [CrossRef]

5. Straumal, B.B.; Korneva, A.; Kilmametov, A.R.; Lityńska-Dobrzyńska, L.; Gornakova, A.S.; Chulist, R.; Karpov, M.I.; Zięba, P. Structural and Mechanical Properties of Ti-Co Alloys Treated by High Pressure Torsion. Materials 2019, 12, 426. [CrossRef] [PubMed]

6. Errandonea, D.; Burakovsky, L.; Preston, D.L.; MacLeod, S.G.; Santamaría-Perez, D.; Chen, S.; Cynn, H.; Simak, S.I.; McMahon, M.I.; Proctor, J.E.; et al. Experimental and theoretical confirmation of an orthorhombic phase transition in niobium at high pressure and temperature. Commun. Mater. 2020, 1. [CrossRef]

7. DIN EN ISO 204-2019-04-Beuth.de. Available online: https://www.beuth.de/de/norm/din-en-iso-204/289976402 (accessed on 8 June 2021).

8. E28 Committee. Test Methods for Conducting Creep, Creep-Rupture, and Stress-Rupture Tests of Metallic Materials; ASTM International: West Conshohocken, PA, USA, 2011.

9. Olbricht, J.; Bismarck, M.; Skrotzki, B. Characterization of the creep properties of heat resistant 9-12\% chromium steels by miniature specimen testing. Mater. Sci. Eng. A 2013, 585, 335-342. [CrossRef]

10. Kurumlu, D. Mechanische und Mikrostrukturelle Untersuchungen an Einer Kurzfaserverstärkten Aluminiumlegierung. Ph.D. Thesis, Ruhr-Universität Bochum, Universitätsbibliothek, Bochum, Germany, 2010.

11. Kurumlu, D.; Payton, E.J.; Young, M.L.; Schöbel, M.; Requena, G.; Eggeler, G. High-temperature strength and damage evolution in short fiber reinforced aluminum alloys studied by miniature creep testing and synchrotron microtomography. Acta Mater. 2012, 60, 67-78. [CrossRef]

12. Mälzer, G.; Hayes, R.W.; Mack, T.; Eggeler, G. Miniature Specimen Assessment of Creep of the Single-Crystal Superalloy LEK 94 in the $1000^{\circ} \mathrm{C}$ Temperature Range. Met. Mat. Trans. A 2007, 38, 314-327. [CrossRef]

13. Hiyoshi, N.; Itoh, T.; Sakane, M.; Tsurui, T.; Tsurui, M.; Hisaka, C. Development of miniature cruciform specimen and testing machine for multiaxial creep investigation. Theor. Appl. Fract. Mech. 2020, 108, 102582. [CrossRef]

14. Hyde, T.H.; Hyde, C.J.; Sun, W. Theoretical basis and practical aspects of small specimen creep testing. J. Strain Anal. Eng. Des. 2013, 48, 112-125. [CrossRef]

15. Morris, A.; Cacciapuoti, B.; Sun, W. The role of small specimen creep testing within a life assessment framework for high temperature power plant. Int. Mater. Rev. 2018, 63, 102-137. [CrossRef]

16. Yu, B.; Han, W.; Tong, Z.; Geng, D.; Wang, C.; Zhao, Y.; Yang, W. Application of Small Specimen Test Technique to Evaluate Creep Behavior of Austenitic Stainless Steel. Materials 2019, 12, 2541. [CrossRef] [PubMed]

17. Chvostová, E.; Džugan, J. Creep test with use of miniaturized specimens. IOP Conf. Ser. Mater. Sci. Eng. 2017, 179, 12032. [CrossRef]

18. Luan, L.; Riesch-Oppermann, H.; Heilmaier, M. Tensile creep of miniaturized specimens. J. Mater. Res. 2017, 32 , 4563-4572. [CrossRef]

19. Kammer, C.; Aluminium-Zentrale, D. Düsseldorf Aluminium-Zentrale; Aluminium: Düsseldorf, Germany, 2000; ISBN 3870172649.

20. Kielbus, A. The influence of ageing on structure and mechanical properties of WE54 alloy. J. Achiev. Mater. Manuf. Eng. 2007, 1, $27-30$. 
21. von Buch, F. Magnesium-Eigenschaften, Anwendungen, Potentiale: Vortragstexte eines Fortbildungsseminars der Deutschen Gesellschaft für Materialkunde e.V. in Zusammenarbeit mit dem Institut für Werkstofforschung des GKSS-Forschungszentrum Geesthacht GmbH. In Eigenschaften von Magnesiumlegierungen und deren Beeinflussung; Kainer, K.U., Ed.; Wiley-VCH: Weinheim, Germany, 2000; ISBN 3527299793.

22. Pekguleryuz, M.O.; Kaya, A.A. Creep Resistant Magnesium Alloys for Powertrain Applications. Adv. Eng. Mater. 2003, 5, 866-878. [CrossRef]

23. Leontis, T.E. The properties of sand cast magnesium-rare earth alloys. JOM 1949, 1, 968-983. [CrossRef]

24. Neite, G.; Kubota, K.; Higashi, K.; Hehmann, F. Magnesium-Based Alloys. In Materials Science and Technology; Cahn, R.W., Haasen, P., Kramer, E.J., Eds.; Wiley-VCH Verlag GmbH \& Co. KGaA: Weinheim, Germany, 2006; ISBN 9783527603978.

25. Polmear, I.J. Light Alloys: Metallurgy of the Light Metals, 2nd ed.; Arnold: London, UK, 1989; ISBN 0340491752.

26. Kennedy, A.J. The Physical Metallurgy of Magnesium and Its Alloys. J. R. Aeronaut. Soc. 1959, 63, 737-738. [CrossRef]

27. Schemme, K. Magnesiumwerkstoffe fur die Neunziger Jahre. Aluminium 1991, 67, 167-178.

28. Kurz, G.; Petersen, T.; Bohlen, J.; Letzig, D. Variation of Rare Earth Elements in the Magnesium Alloy ME21 for the Sheet Production. In Magnesium Technology 2017; Solanki, K.N., Orlov, D., Singh, A., Neelameggham, N.R., Eds.; Springer International Publishing: Berlin/Heidelberg, Germany, 2017; pp. 353-363. ISBN 978-3-319-52391-0.

29. Mo, N.; Tan, Q.; Bermingham, M.; Huang, Y.; Dieringa, H.; Hort, N.; Zhang, M.-X. Current development of creep-resistant magnesium cast alloys: A review. Mater. Des. 2018, 155, 422-442. [CrossRef]

30. Neh, K.; Ullmann, M.; Oswald, M.; Berge, F.; Kawalla, R. Twin Roll Casting and Strip Rolling of Several Magnesium Alloys. Mater. Today Proc. 2015, 2, S45-S52. [CrossRef]

31. Wang, J.G.; Hsiung, L.M.; Nieh, T.G.; Mabuchi, M. Creep of a heat treated Mg-4Y-3RE alloy. Mater. Sci. Eng. A 2001, 315, 81-88. [CrossRef]

32. Kang, Y.H.; Wang, X.X.; Zhang, N.; Yan, H.; Chen, R.S. Effect of initial temper on the creep behavior of precipitation-hardened WE43 alloy. Mater. Sci. Eng. A 2017, 689, 419-426. [CrossRef]

33. Automotive. Available online: https:/ / www.hydro.com/en/aluminium/industries/automotive/ (accessed on 22 June 2021).

34. How is Aluminum Extrusion used in Auto Industry? I AEC. Available online: https://www.aec.org/page/extrusion-applicationsauto-industry (accessed on 22 June 2021).

35. Aluminium Insider. Auto Industry Looks to Aluminum Extrusions for Increased Performance and Cost-Effective SolutionsAluminium Insider. Available online: https://aluminiuminsider.com/auto-industry-looks-to-aluminum-extrusions-forincreased-performance-and-cost-effective-solutions / (accessed on 22 June 2021).

36. Isogai, M.; Murakami, S. Development and application of aluminum extrusion for automotive parts, mainly bumper reinforcement. J. Mater. Process. Technol. 1993, 38, 635-654. [CrossRef]

37. Huppmann, M.; Gall, S.; Müller, S.; Reimers, W. Changes of the texture and the mechanical properties of the extruded Mg alloy ME21 as a function of the process parameters. Mater. Sci. Eng. A 2010, 528, 342-354. [CrossRef]

38. Magnesium WE43-T6, Cast. Available online: http://www.matweb.com/search/datasheet.aspx? matguid=4b8a8c13cf354fc589 3a40cf8eca022c\&ckck=1 (accessed on 23 July 2021).

39. Magnesium WE54-T6, Cast. Available online: http://www.matweb.com/search/datasheet.aspx?matguid=f41ac8bc1ddd4c1d852 47e646b3ec2be (accessed on 23 July 2021).

40. Gall, S. Grundlegende Untersuchungen zum Strangpressen von Magnesiumblechen und deren Weiterverarbeitung: Mikrostruktur und mechanische Eigenschaften. DepositOnce 2013. [CrossRef]

41. Müller, S. Weiterentwicklung des Strangpressens von AZ Magnesiumlegierungen im Hinblick auf eine Optimierung der Mikrostruktur, des Gefüges und der Mechanischen Eigenschaften, 1st ed.; Cuvillier Verlag: Göttingen, Germany, 2007; ISBN 9783736923706.

42. Brömmelhoff, K.; Huppmann, M.; Reimers, W. The effect of heat treatments on the microstructure, texture and mechanical properties of the extruded magnesium alloy ME21. Int. J. Mater. Res. 2011, 102, 1133-1141. [CrossRef]

43. Pyzalla, A.; Camin, B.; Buslaps, T.; Di Michiel, M.; Kaminski, H.; Kottar, A.; Pernack, A.; Reimers, W. Simultaneous tomography and diffraction analysis of creep damage. Science 2005, 308, 92-95. [CrossRef]

44. Huppmann, M.; Camin, B.; Pyzalla, A.R.; Reimers, W. In-situ observation of creep damage evolution in Al-Al2O3 MMCs by synchrotron X-ray microtomography. Int. J. Mater. Res. 2010, 101, 372-379. [CrossRef]

45. Camin, B.; Hansen, L. In Situ 3D- $\mu$-Tomography on Particle-Reinforced Light Metal Matrix Composite Materials under Creep Conditions. Metals 2020, 10, 1034. [CrossRef]

46. Camin, B. In-situ Untersuchung des Schädigungsverhaltens mehrphasiger Werkstoffe unter thermischer und mechanischer Beanspruchung. DepositOnce 2015. [CrossRef]

47. Borbély, A.; Dzieciol, K.; Sket, F.; Isaac, A.; Di Michiel, M.; Buslaps, T.; Kaysser-Pyzalla, A.R. Characterization of creep and creep damage by in-situ microtomography. JOM 2011, 63, 78-84. [CrossRef]

48. Isaac, A.; Sket, F.; Reimers, W.; Camin, B.; Sauthoff, G.; Pyzalla, A.R. In situ 3D quantification of the evolution of creep cavity size, shape, and spatial orientation using synchrotron X-ray tomography. Mater. Sci. Eng. A 2008, 478, 108-118. [CrossRef]

49. Isaac, A.; Sket, F.; Borbély, A.; Sauthoff, G.; Pyzalla, A.R. Study of Cavity Evolution During Creep by Synchrotron Microtomography Using a Volume Correlation Method. Pract. Metallogr. 2008, 45, 242-245. [CrossRef]

50. Stinton, G.W.; MacLeod, S.G.; Cynn, H.; Errandonea, D.; Evans, W.J.; Proctor, J.E.; Meng, Y.; McMahon, M.I. Equation of state and high-pressure/high-temperature phase diagram of magnesium. Phys. Rev. B 2014, 90. [CrossRef] 
51. Abe, F. Development of creep-resistant steels and alloys for use in power plants. Struct. Alloy. Power Plants 2014, $250-293$. [CrossRef]

52. Rösler, J.; Harders, H.; Bäker, M. Mechanisches Verhalten der Werkstoffe, 6th ed.; Springer Vieweg: Wiesbaden, Germany, 2019; ISBN 9783658268015.

53. Maier, H.J.; Niendorf, T.; Bürgel, R. Handbuch Hochtemperatur-Werkstofftechnik: Grundlagen, Werkstoffbeanspruchungen, Hochtemperaturlegierungen und -beschichtungen, 6th ed.; Springer Vieweg: Wiesbaden, Germany, 2019; ISBN 3658253134.

54. Squires, R.L.; Weiner, R.T.; Phillips, M. Grain-boundary denuded zones in a magnesium-wt\% zirconium alloy. J. Nucl. Mater. 1963, 8, 77-80. [CrossRef]

55. Poirier, J.-P. Creep of Crystals; Cambridge University Press (CUP): London, UK, 1985.

56. Wolfenstine, J.; Ruano, O.A.; Wadsworth, J.; Sherby, O.D. Refutation of the relationship between denuded zones and diffusional creep. Scr. Metall. Mater. 1993, 29, 515-520. [CrossRef]

57. Wadsworth, J.; Ruano, O.A.; Sherby, O.D. Denuded zones, diffusional creep, and grain boundary sliding. Metall. Mat. Trans. A 2002, 33, 219-229. [CrossRef]

58. Dunand, D.C.; Han, B.Q.; Jansen, A.M. Monkman-grant analysis of creep fracture in dispersion-strengthened and particulatereinforced aluminum. Metall. Mat. Trans. A 1999, 30, 829-838. [CrossRef]

59. Weertman, J. Theory of Steady-State Creep Based on Dislocation Climb. J. Appl. Phys. 1955, 26, 1213-1217. [CrossRef]

60. Weertman, J. Dislocation Climb Theory of Steady-State Creep. Trans. ASM 1968, 161, 681-694. [CrossRef]

61. Cottrell, A.H. The time laws of creep. J. Mech. Phys. Solids 1952, 1, 53-63. [CrossRef]

62. Gottstein, G. Materialwissenschaft und Werkstofftechnik: Physikalische Grundlagen, 4th ed.; Springer Vieweg: Berlin, Germany, 2014; ISBN 9783642366031.

63. Krompholz, K.; Kalkhof, D. Size effect studies of the creep behaviour of a pressure vessel steel at temperatures from 700 to $900{ }^{\circ} \mathrm{C}$. J. Nucl. Mater. 2002, 305, 112-123. [CrossRef]

64. Meeting on current work on behavior of materials at elevated temperatures. In Size Effect in Creep and Rupture Tests on Unnotched and Notched Specimens of $\mathrm{Cr}-\mathrm{Mo}-\mathrm{V}$ Steel: Reports of Current Work on Behavior of Materials at Elevated Temperatures; Schmieder, A.K. (Ed.) American Society of Mechanical Engineers: New York, NY, USA, 1974.

65. Dymáček, P.; Jarý, M.; Dobeš, F.; Kloc, L. Tensile and Creep Testing of Sanicro 25 Using Miniature Specimens. Materials 2018, 11, 142. [CrossRef]

66. Requena, G.; Telfser, D.; Hörist, C.; Degischer, H.P. Creep behaviour of AA 6061 metal matrix composite alloy and AA 6061. Mater. Sci. Technol. 2002, 18, 515-521. [CrossRef]

67. Cao, L.; Bürger, D.; Wollgramm, P.; Neuking, K.; Eggeler, G. Testing of Ni-base superalloy single crystals with circular notched miniature tensile creep (CNMTC) specimens. Mater. Sci. Eng. A 2018, 712, 223-231. [CrossRef]

68. Randle, V. Twinning-related grain boundary engineering. Acta Mater. 2004, 52, 4067-4081. [CrossRef]

69. Alexandreanu, B.; Sencer, B.H.; Thaveeprungsriporn, V.; Was, G.S. The effect of grain boundary character distribution on the high temperature deformation behavior of Ni-16Cr-9Fe alloys. Acta Mater. 2003, 51, 3831-3848. [CrossRef]

70. Thaveeprungsriporn, V.; Was, G.S. The role of coincidence-site-lattice boundaries in creep of Ni-16Cr-9Fe at $360{ }^{\circ} \mathrm{C}$. Met. Mat. Trans. A 1997, 28, 2101-2112. [CrossRef]

71. Cocks, A.; Ashby, M.F. On creep fracture by void growth. Prog. Mater. Sci. 1982, 27, 189-244. [CrossRef]

72. Kassner, M.E. Fundamentals of Creep in Metals and Alloys, 3rd ed.; Elsevier Science: Amsterdam, The Netherlands, 2015; ISBN 9780080994277.

73. Langdon, T.G. Identifiying creep mechanisms at low stresses. Mater. Sci. Eng. A 2000, 283, 266-273. [CrossRef]

74. Greenwood, G.W. Denuded zones and diffusional creep. Scr. Metall. Mater. 1994, 30, 1527-1530. [CrossRef]

75. Kloc, L. On the symmetry of denuded zones in diffusional creep. Scr. Mater. 1996, 35, 539-541. [CrossRef]

76. Burton, B.; Reynolds, G.L. In defense of diffusional creep. Mater. Sci. Eng. A 1995, 191, 135-141. [CrossRef]

77. Owen, D.M.; Langdon, T.G. Low stress creep behavior: An examination of Nabarro-Herring and Harper-Dorn creep. Mater. Sci. Eng. A 1996, 216, 20-29. [CrossRef] 